NBER WORKING PAPER SERIES

\title{
IMPACTS OF THE AFFORDABLE CARE ACT ON HEALTH INSURANCE COVERAGE IN MEDICAID EXPANSION AND NON-EXPANSION STATES
}

\author{
Charles Courtemanche \\ James Marton \\ Benjamin Ukert \\ Aaron Yelowitz \\ Daniela Zapata \\ Working Paper 22182 \\ http://www.nber.org/papers/w22182 \\ NATIONAL BUREAU OF ECONOMIC RESEARCH \\ 1050 Massachusetts Avenue \\ Cambridge, MA 02138 \\ April 2016
}

We would like to thank Kitt Carpenter, Chad Cotti, Amanda Kowalski, and seminar participants at the 2015 Southern Economic Association Annual Meeting for their valuable comments. The views expressed herein are those of the authors and do not necessarily reflect the views of the National Bureau of Economic Research.

NBER working papers are circulated for discussion and comment purposes. They have not been peer-reviewed or been subject to the review by the NBER Board of Directors that accompanies official NBER publications.

(C) 2016 by Charles Courtemanche, James Marton, Benjamin Ukert, Aaron Yelowitz, and Daniela Zapata. All rights reserved. Short sections of text, not to exceed two paragraphs, may be quoted without explicit permission provided that full credit, including () notice, is given to the source. 
Impacts of the Affordable Care Act on Health Insurance Coverage in Medicaid Expansion and Non-Expansion States

Charles Courtemanche, James Marton, Benjamin Ukert, Aaron Yelowitz, and Daniela Zapata NBER Working Paper No. 22182

April 2016

JEL No. I13

\section{$\underline{\text { ABSTRACT }}$}

The Affordable Care Act (ACA) aimed to achieve nearly universal health insurance coverage in the United States through a combination of insurance market reforms, mandates, subsidies, health insurance exchanges, and Medicaid expansions, most of which took effect in 2014. This paper estimates the causal effects of the ACA on health insurance coverage using data from the American Community Survey. We utilize difference-in-difference-in-differences models that exploit cross-sectional variation in the intensity of treatment arising from state participation in the Medicaid expansion and local area pre-ACA uninsured rates. This strategy allows us to identify the effects of the ACA in both Medicaid expansion and non-expansion states. Our preferred specification suggests that, at the average pre-treatment uninsured rate, the full ACA increased the proportion of residents with insurance by 5.9 percentage points compared to 3.0 percentage points in states that did not expand Medicaid. Private insurance expansions from the ACA were due to increases in both employer-provided and non-group coverage. The coverage gains from the full ACA were largest for those with incomes below the Medicaid eligibility threshold, nonwhites, young adults, and unmarried individuals. We find some evidence that the Medicaid expansion partially crowded out private coverage among low-income individuals.

Charles Courtemanche

Georgia State University

Andrew Young School of Policy Studies

Department of Economics

P.O. Box 3992

Atlanta, GA 30302-3992

and NBER

ccourtemanche@gsu.edu

James Marton

Georgia State University

Andrew Young School of Policy Studies

Department of Economics

P.O. Box 3992

Atlanta, GA 30302-3992

marton@gsu.edu

Benjamin Ukert

Georgia State University

Andrew Young School of Policy Studies

Department of Economics

P.O. Box 3992

Atlanta, GA 30302-3992

bukert1@student.gsu.edu
Aaron Yelowitz

University of Kentucky

Department of Economics

335 Business and Economics Building

Lexington, KY 40506-0034

aaron@uky.edu

Daniela Zapata

Impaq International

1101 Vermont Avenue

11th Floor

Washington, DC 20005

dzapata@impaqint.com 


\section{INTRODUCTION}

The goal of the Patient Protection and Affordable Care Act (ACA) of March 2010 is to achieve nearly universal health insurance coverage in the United States through a combination of insurance market reforms, mandates, subsidies, health insurance exchanges, and Medicaid expansions (Gruber, 2011). These major components of the ACA all took effect in 2014, with the Medicaid expansion being optional for states. ${ }^{1}$ This paper uses data from the American Community Survey (ACS) to evaluate the first-year impacts of the ACA on health insurance coverage levels and sources in both states that expanded Medicaid and those that did not.

The first component of the ACA's "three-legged stool" involves reforms designed to improve the functioning of the non-group insurance market for consumers who did not have access to employer-provided or public coverage (Gruber, 2011). Insurance market regulations implemented in 2014 such as community rating, guaranteed issue, and minimum coverage requirements aim to ensure the availability of adequate insurance for those with pre-existing conditions. ${ }^{2}$ The law also established a Health Insurance Marketplace, commonly referred to as the "Federal Exchange", to facilitate insurance purchases for individuals and small businesses and stimulate competition among insurance plans. ${ }^{3}$ Each state was given the option of establishing their own insurance exchange and 15 states did so in 2014 (KFF, 2014).

These reforms alone would likely lead to an adverse selection death spiral, as an influx of high-cost beneficiaries would drive up premiums for those remaining in the insurance pool (Gruber, 2011). This concern motivated the second leg of the three-legged school: the individual

\footnotetext{
${ }^{1}$ The June 2012 U.S. Supreme Court ruling in NFIB v. Sebelius rendered the ACA Medicaid expansion optional for states (NFIB v. Sebelius, 567 U.S. _ (2012), 132 S.Ct 2566). As of September 2015, 30 states and the District of Columbia have expanded their Medicaid program (MACPAC, 2015).

${ }^{2}$ For more on the timing of various components of the ACA, see: $\mathrm{http} / / / \mathrm{kff}$. org/interactive/implementation-timeline/

${ }^{3}$ For further details, see http://www.hhs.gov/healthcare/facts-and-features/key-features-of-aca-by-year/index.html
} 
mandate. ${ }^{4}$ Beginning in 2014, individuals deemed to be able to afford coverage but electing to remain uncovered were penalized. The penalty varies with income but can reach as high as the total annual premium for the national average price of a Bronze exchange plan. ${ }^{5}$

Mandating insurance coverage leads to concerns about affordability, which the third leg of the three-legged stool aims to address through subsidies and Medicaid expansions. Sliding scale subsidies in the form of tax credits are available to consumers in every state with incomes between 100 and 400 percent of the Federal Poverty Line (FPL) who do not qualify for other affordable coverage. ${ }^{6}$ In states that opted to expand Medicaid via the ACA, those with income below 138 percent FPL are eligible for Medicaid coverage. Previously, Medicaid eligibility was typically tied to those with low income among specific groups, such as children, single mothers, pregnant women, and the elderly. This suggests a major expansion of Medicaid eligibility via the ACA for low income childless adults and married adults with children.

We estimate the effects of the ACA both with and without the Medicaid expansion using a difference-in-difference-in-differences model with the differences coming from time, state Medicaid expansion status, and local area pre-treatment uninsured rate. This last source of variation, which arises because universal coverage initiatives provide the most intense treatments in areas with high baseline uninsured rates, allows us to disentangle the causal effect of the ACA from the underlying time trend while also accounting for the possible endogeneity of state Medicaid expansion decisions. Finkelstein (2007) uses a similar "bite" strategy to identify the

\footnotetext{
${ }^{4}$ There is also an employer mandate which will impose a financial penalty on employers with more than 50 employees that have at least one full-time employee who receives a premium tax credit. Implementation of this mandate was delayed until January 1, 2015 for businesses with more than 100 employees and January 1, 2016 for those with 50 to 99 . More information is available at http://kff.org/interactive/implementation-timeline/ ${ }^{5}$ Specifically, in 2014 the penalty was the greater of 1) $1 \%$ of household income up to a maximum of the national average annual premium for a Bronze plan, or 2) $\$ 95$ per adult plus $\$ 47.50$ per child up to a maximum of $\$ 285$. The $\$ 285$ maximum increased to $\$ 975$ in 2015 and \$2,085 in 2016. For more information, see: https://www.healthcare.gov/fees/fee-for-not-being-covered/

${ }^{6}$ See http://www.hhs.gov/healthcare/facts-and-features/key-features-of-aca-by-year/index.html\#2014
} 
impact of Medicare on health care spending. Miller (2012) also uses this approach to estimate the impact of the Massachusetts reform on emergency room utilization without control states.

The ACS is well suited for our study for several reasons. First, it includes multiple categories of health insurance coverage, allowing for an examination of how the ACA affected both private and public coverage (e.g. via exchanges and Medicaid expansions). The ACS also precisely measures income, allowing us to finely distinguish how the statutory ACA rules changed public and private eligibility. Additionally, with approximately 3,000,000 observations per year and relatively narrow geographic identifiers, the ACS is large enough to precisely estimate the effects for states and many localities. Finally, the ACS is a mandatory survey, greatly reducing concerns about sample selection amongst respondents.

In our full-sample regressions, we estimate that the ACA including the Medicaid expansion increased insurance coverage by 5.9 percentage points at the sample mean pretreatment uninsured rate, with the effect reaching as high as 15.4 percentage points in the area with the largest uninsured rate. The effect of the ACA without the Medicaid expansion was only 3.0 percentage points at the mean uninsured rate, reaching as high as 7.8 percentage points. Coverage gains in non-Medicaid expansion states came entirely from private insurance, split between employer-provided and non-group coverage. Gains from the Medicaid expansion are exclusively attributable to increased Medicaid coverage. These results all remain similar across a range of robustness checks and pass falsification tests for differential pre-treatment trends. We also conduct subsample analyses and find that the increases in coverage from the full ACA were largest for those with incomes below the ACA's Medicaid eligibility threshold, non-whites, 1834 year olds, and unmarried individuals. In non-Medicaid-expansion states, coverage gains among low-income individuals were no larger than those for middle-income individuals. Among 
the low-income subsample, some evidence suggests that a portion of the gain in Medicaid coverage from the Medicaid expansion was crowded out by reduced private coverage.

\section{LITERATURE REVIEW}

There is an extensive literature spanning several decades examining the impact of policies designed to increase insurance coverage on the receipt of both public and private insurance coverage. Buchmueller et al. (2015) provides a thorough review of studies that focus on the impact of expansions of the Medicaid program over time, as well as other Medicaid policy changes that may impact public and / or private insurance coverage. ${ }^{7}$ A large part of this literature examines the impact of Medicaid expansions of the late 1980s and early 1990s on coverage gains for children. As summarized by Buchmueller et al. (2015), estimates of the marginal Medicaid take-up rate among children made newly eligible for Medicaid are characterized as being fairly modest, ranging between 15 and 24 percent. $^{8}$ There is less agreement on the magnitude of "crowd out" in this literature, but even the largest estimates of the marginal loss of private coverage caused by increased Medicaid eligibility are generally below 10 percent. Rescaling this marginal crowd out estimate by the Medicaid take-up rate leads to estimates of the crowd out rate between 42 percent $(=.10 / .24)$ and 67 percent $(=.10 / .15){ }^{9}$

A recent state expansion of coverage that has received a great deal of attention in the literature is the Massachusetts insurance market reform of 2006, which served as the model for the ACA. Long, Stockely, and Yemane (2009) find that by 2008 the uninsured rate decreased by 6.6 percentage points for the overall nonelderly population in Massachusetts. Courtemanche and

\footnotetext{
${ }^{7}$ We will not focus on these other Medicaid policy changes, but they include outreach (Aizer, 2007), application process changes (Mishra et al., 2014), waiting periods (Wolfe and Scrivner, 2005), premiums and other forms of cost sharing (Kenney et al., 2006; Marton, 2007; Marton et al., 2015), citizenship verification (Sommers, 2010; Marton, Snyder, and Zhou, 2016), and managed care implementation (Marton et al., 2014; Marton et al., 2016). ${ }^{8}$ Cutler and Gruber (1996) is the seminal paper in this literature.

${ }^{9}$ There is also a smaller literature (Busch and Duchovny, 2005 and Hamersma and Kim, 2013) that studies the national impact of public coverage expansions on non-elderly adults, primarily parents.
} 
Zapata (2014) estimate that the Massachusetts reform led to an increase in coverage of 5.6 percentage points for the nonelderly population over a longer time period (July 2007 - December 2010) beginning after the final major component of the reform (the individual mandate) took effect. Yelowitz and Cannon (2010) explore the possibility that the reform's impact was mitigated by crowd-out among the low-income and find evidence supporting this view.

Most prior research on the ACA focuses on the only substantial component of its coverage expansion to be implemented before 2014: the 2010 mandate for private insurers to allow young adults to stay on their parents' insurance until turning 26. Several studies suggest that the dependent coverage provision increased insurance coverage among 19-25 year olds by 3-5 percentage points, with the effect being largest among those at the high end of this age range (Akosa Antwi et al., 2013; Sommers et al., 2013; Barbaresco, Courtemanche, and Qi, 2015).

There is much less evidence on the effects of the ACA's insurance expansions for the broader population of non-elderly adults, since these did not take effect until 2014. A few recent studies have conducted simple before-and-after comparisons of insurance status. Long et al. (2014) compare coverage rates in September 2013 to September 2014 and find an overall increase in coverage of 5.3 percentage points among nonelderly adults using data from the Urban Institute Health Reform Monitoring Survey. Within Medicaid expansion states, they estimate the increase in coverage to be 5.8 percentage points, compared to 4.8 percentage points in nonexpansion states. Smith and Medalia (2015) use the Current Population Survey Annual Social and Economic Supplement to examine changes in insurance coverage between 2013 and 2014 for everyone in the US, including both children and the elderly. They estimate an overall 2.9 percentage point increase in coverage, which is a combination of a 3.4 percentage point increase in expansion states and a 2.3 percentage point increase in non-expansion states. Courtemanche et 
al. (2016) find a similar 2.8 percentage point increase in insurance coverage nationally across all ages using data from the American Community Survey.

A major limitation of these descriptive studies is that, since insurance coverage rates naturally fluctuate over time, the extent to which their estimates reflect causal effects of the ACA as opposed to other factors is unclear. For instance, the unemployment rate dropped from 8 percent to 5.6 percent between the start of 2013 and the end of $2014 .{ }^{10}$ We might therefore have expected increases in employer-provided and overall coverage and a drop in Medicaid coverage in 2014 if the ACA had not occurred. Other confounding factors might include demographic shifts and the underlying upward trend in health insurance premiums.

We are aware of only one study, a newly released working paper written concurrently to ours (Kaestner et al., 2015), that aims to identify the causal effect of a 2014 component of the ACA on health insurance coverage. However, Kaestner et al. (2015) focus only on the ACA's Medicaid expansion, as opposed to the law in general. They utilize difference-in-difference and synthetic control methods and a sample of individuals with no further than a high school education from the American Community Survey and Current Population Survey. Among this sample, they find that the Medicaid expansion increased Medicaid coverage by approximately 4 percentage points, decreased the proportion uninsured by approximately 3 percentage points, and decreased private health insurance coverage by 1 percentage point.

Our paper offers several contributions relative to Kaestner et al. (2015). First, Kaestner et al. (2015) only develop a causal framework for the Medicaid expansion portion of the ACA and consequently only include individuals with no more than a high school education in their sample. In contrast, we utilize the full sample of non-elderly adults and develop an identification strategy designed to estimate the causal effect of not only the Medicaid expansion but also the law's

\footnotetext{
${ }^{10}$ See http://data.bls.gov/timeseries/LNS14000000
} 
private portion (combination of insurance market reforms, exchanges, mandates, and subsidies).

This means we are also the first to estimate the overall causal effect of the fully implemented ACA as well as what share of the coverage gains can be attributed to the private versus Medicaid components. Next, our triple-difference approach offers an alternative identification strategy for the Medicaid expansion effect that relies on weaker assumptions than a difference-in-differences model. Specifically, we do not need to assume that Medicaid expansion and non-expansion states shared common counterfactual trends; we instead only need to assume that, to whatever extent such differential trends exist, the difference is not correlated with pre-treatment uninsured rates. The fact that we ultimately find similar Medicaid effects to Kaestner et al. (2015) adds further robustness to their findings. Third, while they consider only two types of coverage - Medicaid and private - we further distinguish whether the gains in private coverage were from employerprovided or private insurance coverage. Finally, we consider heterogeneity along several new dimensions, as Kaestner et al. (2015) do not stratify by income, gender, or race. ${ }^{11}$

\section{DATA}

Our primary data source is the American Community Survey ("ACS"), a nationwide survey administered by the Census Bureau asking detailed questions about population and housing characteristics. The ACS samples approximately one percent of the U.S. population. Like the decennial Census, participation is mandatory, and the survey can be completed online or by mailing in a paper questionnaire. ${ }^{12}$ The ACS identifies all 50 states and the District of

\footnotetext{
${ }^{11}$ Note that one way in which Kaestner et al. (2015) go further than our paper is that they consider effects of the ACA's Medicaid expansion on labor supply while we do not. This is because we do not think our identification strategy - which relies on variation in pre-ACA uninsured rates - is appropriate to study labor market outcomes. Our approach implicitly assumes that the effects are limited to those who lacked insurance coverage prior to the ACA, and labor supply effects may occur along several other dimensions (e.g. those who have always been insured but cut back their work hours due to the availability of subsidized insurance in the exchanges).

${ }^{12}$ In-person interviews are done with respondents in group quarters, such as college dormitories, nursing homes, and prisons. See https://www.census.gov/content/dam/Census/programs-surveys/acs/about/ACS_Information_Guide.pdf
} 
Columbia, and additionally identifies localities known as Public Use Microdata Areas (PUMAs) - approximately 2,300 areas of at least 100,000 people nested entirely within a state. ${ }^{13}$

The ACS is appealing for our study because its large number of observations, over $3,000,000$ individuals per year, allows us to precisely estimate the effects of different aspects of the ACA. This is important since only a fraction of the total population is affected by the changes resulting from the ACA, limiting plausible effect sizes. Our main sample consists of 18-64 year olds from calendar years 2011 to 2014 . We exclude individuals older than 64 since the ACA was not intended to affect the health care coverage of seniors. We selected 2011 as the first year of our sample because we did not want the relatively smaller pieces of the ACA implemented in 2010, such as the dependent coverage mandate, the removal of copays on preventive services, and the review of health plan premium increases, to confound our estimates of the major components of the ACA that were implemented in 2014.

For each individual, the ACS asks: "Is this person CURRENTLY covered by any of the following types of health insurance or health coverage plans?" where choices include "insurance though a current or former employer or union", "insurance purchased directly from an insurance company", "Medicare", "Medicaid, Medical Assistance, or any kind of government-assistance plan for those with low incomes or a disability", "TRICARE or other military health care", "VA (including those who have ever used or enrolled for VA health care)", "Indian Health Service", and "any other type of health insurance or health coverage plan." An individual may choose more than one source of coverage, and only those answering "no" to every type of insurance are considered uninsured. Using these responses, we create several binary outcome variables: any insurance, any private insurance (either employer-sponsored or directly purchased), employer-

\footnotetext{
${ }^{13}$ For more information, see: https://www.census.gov/geo/reference/puma.html
} 
sponsored insurance, directly purchased insurance, Medicaid, and any other coverage. These categories are not mutually exclusive due to the possibility of multiple sources of coverage.

The structure of this ACS question was constant for the entire period between 2011 and 2014. In contrast, as noted in Smith and Medalia (2014), the Current Population Survey Annual Social and Economic Supplement (CPS ASEC) was redesigned in 2013, leading to difficulties in comparing estimates of health insurance coverage over time. In addition, the ACS has the advantage of explicitly asking about current coverage. As Swartz (1986) notes, the CPS question is widely misinterpreted as asking about current coverage, when in fact, it asks about coverage at any point during the previous calendar year.

A critical variable for our identification strategy is the uninsured rate in the respondent's "local area" in the last pre-treatment year of 2013. Due to new boundaries arising from the 2010 Census, the PUMA classification system changed during our sample period in a way that makes it impossible for us to simply use PUMAs as the local areas. ${ }^{14}$ Instead, we use both the old and new PUMA classification systems to identify core-based statistical areas (CBSAs), which we then use to define our local areas. ${ }^{15}$ If a CBSA spans multiple states, we define a different local area for the parts of the CBSA in each state; e.g. the Missouri and Illinois portions of the St. Louis region are classified as separate areas. To prevent respondents who do not live in a CBSA from being dropped, we create additional local areas for the non-CBSA portion of each state (e.g. rural Georgia). In total, this process yields 630 local areas that each contain between 364 and

\footnotetext{
${ }^{14}$ The new 2010 Census boundaries generate 2,351 unique PUMAs, whereas the pre-2010 boundaries generated 2,071 unique PUMAs. These new boundaries are applicable to the 2013 ACS and beyond. For more on these geographic constructs, see: https://ask.census.gov/faq.php?id=5000\&faqId=1673

${ }^{15}$ For each PUMA, both before and after the 2010 boundary change, we associated it with the CBSA that had the largest share of population within the PUMA. More than 99 percent of PUMAs map into at least one CBSA. Each PUMA is associated with up to 6 CBSAs, however approximately 80 percent of PUMAs, containing 79.1 percent of the US population, map into precisely one CBSA. Nearly 11 percent of PUMAs map into two CBSAs, with the remaining 8.5 percent mapping into 3 to 6 CBSAs.
} 
80,505 respondents in the 2013 wave, with a median of 1,036 and a mean of 2,864. Pre-treatment uninsured rates are therefore computed from a reasonably large sample for all areas.

Our state-level ACA variables come from the Kaiser Family Foundation, a non-profit organization that collects a vast array of health policy information. This information includes whether a state implemented the Medicaid expansion as well as whether this expansion was done through private insurance via a Section 1115 waiver. Expanding under the Section 1115 waiver, as done by Arkansas, Iowa, and Michigan, introduced cost sharing and premiums for enrollees and could therefore have had different effects than expanding via traditional Medicaid. We attempted to test for such differences but were unable to draw clear conclusions; we therefore simply classify the Section 1115 waiver states as being Medicaid expanders. All states' Medicaid expansions were effective on January 1, 2014 except Michigan's, which took effect in April. Our results remain virtually identical if we drop Michigan from the sample.

We include a wide range of control variables. The controls from the ACS reflect demographic characteristics (dummy variables for age groups, gender, and race/ethnicity), family structure (marital status and dummies for number of children in the household), and economic/labor force characteristics (dummies for education and household income category, whether the respondent reports her primary occupation as student, and whether the respondent is unemployed). We also control for the Bureau of Labor Statistics' seasonally adjusted monthly state unemployment rate. Finally, we control for interactions of the post-treatment dummy with indicators of whether states set up their own private insurance exchanges (as opposed to using the federal exchange) and whether these exchanges experienced glitches. These controls aim to address the possible concern that the decision to expand Medicaid might be correlated with other, harder-to-measure aspects of state involvement with the ACA (e.g. degree of outreach) 
that could separately influence insurance coverage or health-related outcomes. This information comes from the Kaiser Family Foundation and Kowalski (2014).

Tables 1 and 2 provide pre-treatment means and standard deviations of the dependent variables and controls, respectively. We also report the summary statistics stratified by state Medicaid expansion status and local area pre-treatment uninsured rate. Residents of Medicaid expansion states and areas with pre-ACA uninsured rates below the median were more likely to be insured, had higher incomes, and were also more educated. Our econometric design will account for these baseline differences.

Figure 1 presents changes in our insurance variables of interest during the sample period. The pre-ACA trends do not appear to differ by Medicaid expansion status or pre-treatment uninsured rate, providing preliminary support for the use of these variables as sources of identification. Increases in the probabilities of having any coverage, privately purchased coverage, any private coverage, and Medicaid are evident in 2014. We next turn to regression analyses to identify the extent to which these increases represent causal effects of the ACA.

\section{FULL-SAMPLE ANALYSES}

\section{A. Baseline Models}

For each insurance coverage outcome, our econometric objectives are to estimate the effects of both the fully implemented ACA (including the Medicaid expansion) and the ACA without the Medicaid expansion. We begin with a simple but likely naïve difference-indifferences (DD) specification:

$$
y_{\text {iast }}=\beta_{0}+\beta_{1} \text { POST }_{t}+\beta_{2}\left(\text { MEDICAID }_{s} * \text { POST }_{t}\right)+\boldsymbol{\beta}_{\mathbf{3}} \boldsymbol{X}_{\text {iast }}+\alpha_{a s}+\varepsilon_{\text {iast }}
$$

where $y_{\text {iast }}$ is the outcome for individual $i$ in local area $a$ in state $s$ in year $t, P_{t}$ is an indicator for whether period $t$ is in the post-treatment year of 2014, MEDICAID is an indicator 
for whether state $s$ participated in the ACA's Medicaid expansion, $\boldsymbol{X}_{\boldsymbol{i a s t}}$ is a vector of control variables, $\alpha_{a s}$ is a local area fixed effect, and $\varepsilon_{\text {iast }}$ is the error term. Note that we do not need to separately include $M E D I C A I D_{S}$ in the model since it would be perfectly collinear with the local area fixed effects (recall that local areas are nested within states); our results are very similar if we drop the area fixed effects and include $M E D I C A I D_{S}$ instead. Standard errors are heteroscedasticity-robust and clustered by state.

In equation (1), $\beta_{1}$ represents the effect of the non-Medicaid components of the ACA (insurance market reforms, individual mandate, subsidies, exchanges) while $\beta_{2}$ is the effect of the Medicaid expansion. $\beta_{1}+\beta_{2}$, therefore, gives the impact of the fully implemented ACA, whereas $\beta_{1}$ is the impact of the ACA without the Medicaid expansion. $\hat{\beta}_{2}$ has a causal interpretation under the usual difference-in-differences identifying assumption that, conditional on the other covariates, changes in the outcomes in 2014 would have been the same in expansion and non-expansion states if the expansion had not occurred. Interpreting $\hat{\beta}_{1}$ as causal, however, requires the more problematic assumption that there would have been no changes in the outcomes in 2014 in the absence of the ACA, conditional on the controls. This assumption seems unlikely to hold since patterns of insurance coverage would be expected to change from year to year for many reasons, such as macroeconomic conditions and the upward trend in premiums.

Our preferred specification is therefore a difference-in-difference-in-differences (DDD) design that aims to disentangle these year-to-year changes from the causal effect of the nonMedicaid portions of the ACA. We do this by exploiting variation in the intensity of treatment arising from differential pre-treatment (2013) uninsured rates across local areas, following the Finkelstein (2007) and Miller (2012) studies of the effects of the introduction of Medicare and the Massachusetts health care reform, respectively. Adding this layer of geographic variation in 
the effect of the non-Medicaid portion of the ACA allows us to include time period fixed effects to capture nationwide changes in the outcomes that would have occurred if the ACA had not been implemented. Assuming that the extent of an area's treatment is proportional to its baseline uninsured rate, the DDD model is:

$$
\begin{gathered}
y_{\text {iast }}=\gamma_{0}+\gamma_{1}\left(\text { UNINSURED }_{a s} * \text { POST }_{t}\right)+\gamma_{2}\left(\text { MEDICAID }_{s} * \text { POST }_{t}\right)+\gamma_{3}\left(\text { UNINSURED }_{a s} *\right. \\
\left.M E D I C A I D_{s} * \text { POST }_{t}\right)+\gamma_{\mathbf{4}} \boldsymbol{X}_{\text {iast }}+\tau_{\tau}+\alpha_{a s}+\varepsilon_{\text {iast }}
\end{gathered}
$$

where UNINSURED $_{a s}$ is the 2013 uninsured rate in local area $a$ in state $s$ and $\tau_{\tau}$ is a year fixed effect. Note that $\mathrm{POST}_{t}$ is no longer included in the model since it is perfectly collinear with the year fixed effects, while $M E D I C A I D_{s}, U N I N S U R E D_{s}$, and $U N I N S U R E D_{s} * M E D I C A I D_{s}$ are not separately included since they are perfectly collinear with the area fixed effects.

In equation (2), the effect of the ACA without the Medicaid expansion is given by $\gamma_{1} * U N I N S U R E D_{a s}$, which means it is assumed to be 0 in a (hypothetical) area with a 0 percent uninsured rate at baseline and to increase linearly as the pre-ACA uninsured rate rises. ${ }^{16}$ The identifying assumption for the impact of the non-Medicaid expansion components of the ACA is therefore that, in the absence of the treatment, any changes in the outcomes that would have occurred in 2014 would not have varied differentially by state uninsured rates, conditional on the controls. This strikes us as a more defensible assumption than the one from equation (1) that there would have been no changes at all in 2014 .

Similarly, the effect of the Medicaid expansion is given by $\gamma_{3} * U N I N S U R E D_{a s}$. As is the case with the private portion of the ACA, the impact of the Medicaid expansion is now assumed to vary linearly with the state's baseline uninsured rate. Since it seems reasonable that

\footnotetext{
${ }^{16}$ Local area pre-ACA uninsured rates reach as low as 3 percent in our data, so we do observe areas that are reasonably close to the hypothetical 0 percent. We have experimented with non-linear functional forms (e.g. quadratic, including a series of dummy variables) for the uninsured rate and found that they do not reveal any meaningful new information.
} 
the Medicaid expansion should not impact insurance coverage in areas with a 0 percent baseline uninsured rate, we consider $\gamma_{2}$ to capture unobserved confounders rather than representing part of the expansion's causal effect. ${ }^{17}$ Our identifying assumption for the impact of the Medicaid expansion is therefore that, to whatever extent insurance would have changed differently in expansion versus non-expansion states in the absence of the ACA, these differences were not systematically correlated with pre-ACA uninsured rates (conditional on the controls). This is a weaker assumption than that of the difference-in-differences model from equation (1), which requires no differential changes between expansion and non-expansion states.

\section{B. Robustness Checks}

We also estimate a number of variants of equation (2) as robustness checks. Most of these checks experiment with dropping certain sets of control variables since many - such as income, unemployment, student status, marital status, and possibly even number of children - could be endogenous to the ACA and therefore lead to an over-controlling problem. Our sparsest model includes only the most obviously exogenous controls, which are the demographic characteristics age, gender, and race/ethnicity. To isolate the influence of each of the other categories of controls, we also estimate models with demographic and family characteristics, demographic and economic characteristics, and demographic characteristics plus the state exchange variables.

Our final robustness check addresses the issue of whether it is appropriate to interact both $\mathrm{POST}_{t}$ and $M E D I C A I D_{s} * \mathrm{POST}_{t}$ with the same uninsured rate variable since the Medicaid expansion and non-Medicaid expansion components of the ACA applied to different populations. Specifically, the Medicaid expansion was for those below 138 percent of the Federal Poverty Line (FPL) while the exchanges and subsidies were for those above 100 percent FPL. We

\footnotetext{
${ }^{17}$ Not considering our estimate of $\gamma_{2}$ to be interpretable as a causal effect is consistent with the interpretation used by Miller (2012) in her study that used a pre-treatment uninsured rate-based strategy to estimate the effects of the Massachusetts health care reform.
} 
therefore interact $\mathrm{POST}_{t}$ with the pre-ACA uninsured rate for respondents in our dataset above 100 percent FPL and MEDICAID P POST $_{t}$ with the rate for those below 138 percent FPL. We prefer to use this as a robustness check rather than our main model for three reasons. First, our income variable is self-reported and could therefore be subject to measurement error. Second, we observe gross income whereas the ACA cutoffs are based on modified adjusted gross income, so the delineations are not exact. ${ }^{18}$ Third, some components of the ACA - such as the individual mandate - could affect uninsured individuals throughout the income distribution. In any event, the baseline uninsured rates for those above 100 percent FPL and below 138 percent FPL have a very high correlation of 0.8 so we expect the results to remain similar.

\section{Results}

The discussion of our regression results begins with an examination of the estimated effects of the ACA on the probability of respondents having any insurance coverage reported in table 3. The top panel presents the coefficient estimates for the treatment variables. The bottom panel uses these estimates to compute the implied effects of the private (non-Medicaid expansion) and Medicaid expansion components of the ACA, as well as the full (private plus Medicaid expansion) ACA, at the sample mean pre-treatment uninsured rate. For the DDD specifications, the estimated effects of the private portion, Medicaid portion, and full ACA at the mean are $\gamma_{1} * \overline{U N I N S U R E D}_{a s}, \gamma_{3} * \overline{U N I N S U R E D}_{a s}$ and $\left(\gamma_{1}+\gamma_{3}\right) * \overline{U N I N S U R E D}_{a s}$, respectively, where $\overline{U N I N S U R E D}_{a s}=0.203$ or 20.3 percent. ${ }^{19}$

The first column of table 3 provides the estimates from our "naïve" difference-indifferences specification represented by equation (1). Our coefficient estimate for the post-

\footnotetext{
${ }^{18}$ For further detail, see http://laborcenter.berkeley.edu/pdf/2013/MAGI_summary13.pdf

${ }^{19}$ We have also computed the average effects across all individuals in the sample (using each individual's local area pre-treatment uninsured rate) and found them to be very similar to the effects at the mean. We therefore do not report both numbers.
} 
reform indicator $\left(\beta_{1}\right)$ suggests that the 2014 implementation of the non-Medicaid expansion components of the ACA was associated with a 2.7 percentage point increase in the probability of having insurance. The coefficient estimate for the Medicaid expansion / post-reform interaction $\left(\beta_{2}\right)$ suggests that the choice to expand Medicaid in 2014 was associated with an additional 0.9 percentage point increase in insurance coverage for the typical expansion state. Taken together, these coefficient estimates $\left(\hat{\beta}_{1}+\hat{\beta}_{2}\right)$ suggest that full implementation of the ACA was associated with a 3.6 percentage point increase in coverage among non-elderly adults, which represents a 4.5 percent increase relative to the pre-2014 average coverage rate of 80.4 percent.

As discussed previously, we are hesitant to give these estimates a causal interpretation. We therefore report in the second column of table 3 the results from our preferred DDD specification with a complete set of controls. In an area with the average pre-treatment uninsured rate, we estimate that the non-Medicaid expansion components of the ACA increased the coverage rate by 3.0 percentage points while the Medicaid expansion added another 2.9 percentage points. Thus, fully implementing the ACA increased insurance coverage by 5.9 percentage points (or 7.3 percent). The naïve DD model therefore appears to substantially understate the effect of the Medicaid expansion, and consequently the effect of the full ACA as well. It is interesting, and perhaps surprising, that switching from the DD to the DDD specification leads to a more substantial change in the estimate for the Medicaid expansion than that for the non-Medicaid part of the ACA. Omitting UNINSURED $* P O S T_{t}$ in equation (1) therefore appears to lead to a downward bias in the estimated Medicaid effect. This occurs because states with high baseline uninsured rates were less likely to adopt the Medicaid expansion: the correlation between UNINSURED $D_{a s}$ and $M E D I C A I D_{S}$ is -0.113 . 
The next five columns in table 3 present the results from the robustness checks. Our estimates remain similar and are statistically significant in all cases. At the mean pre-treatment uninsured rate, the estimated effect of the full ACA effect on the probability of having any insurance coverage varies from 5.7 to 6.2 percentage points across these different specifications. The estimated effects of the non-Medicaid and Medicaid components range from 2.9 to 3.3 percentage points and 2.3 to 3.0 percentage points, respectively.

Table 4 shows the estimated effects of the ACA on the sources of health insurance coverage using our preferred DDD specification with a complete set of controls. Tables A1 to A5 in the online appendix present the results from the other specifications for these outcomes. The first column of table 4 shows the results for private health insurance, regardless of whether the coverage is provided by the employer (ESI) or individually purchased. The second and third columns show the effects of the ACA on these two types of coverage separately. The fourth column shows the results for Medicaid coverage, and the fifth shows the effect on any other sources of coverage. Recall that these sources of coverage are not mutually exclusive, so we should not expect, for instance, the sum of the effects on all these sources to be exactly equal to the overall increase in coverage estimated in table 3 . This is also the reason why we do not consider econometric models for mutually exclusive choices such as multinomial logits.

Our results suggest that the full implementation of the ACA is predicted to increase private insurance coverage by 2.4 percentage points (from the base of 67.2 percent reported in table 1) in an area with the mean pre-treatment uninsured rate. Surprisingly, this increase in private health insurance coverage is mainly due to an increase in ESI rather than additional privately purchased coverage via the exchanges. On average, ESI increased 1.6 percentage points (from a base of 59.8 percent), while individually purchased insurance increased 0.9 percentage 
points (from a base of 9.6 percent). One possible explanation for the relatively large increase in ESI is the individual mandate, which could increase take-up among employees, their spouses, or their dependents. The employer mandate is not a likely explanation since it had not yet taken effect in 2014, though voluntary early compliance is possible. Another interesting result from the regressions for private sources of coverage is that we find no evidence of crowd-out from the Medicaid expansion. The effects of the Medicaid expansion on having any private coverage, ESI, and individually purchased insurance are all very small and not statistically significant (-0.0004 percentage points for any private coverage, 0.003 for ESI, and -0.002 for individually purchased insurance at the mean uninsured rate).

Results from the fourth column of table 4 suggest that the ACA Medicaid expansion increased Medicaid enrollment by 3.2 percentage points ( 28 percent of the base of 11.4 percent) at the mean pre-treatment uninsured rate. In addition, our results show that the fully implemented ACA increases the probability of having Medicaid coverage by 3.8 percentage points, with the remaining 0.6 percentage points coming the private portion (though the estimate for the private portion is not quite statistically significant). It seems plausible that the ACA could have induced modest increases in Medicaid take-up - due to the individual mandate or simply heightened awareness of coverage options- even in states that opted out of the Medicaid expansion. ${ }^{20}$

The last column of table 4 shows that there is no evidence that the ACA affected the probability of having other sources of coverage (e.g. Medicare, Tricare, VA). The estimated effects of the Medicaid expansion and non-Medicaid expansion components, as well as the full ACA, are all very small and insignificant. These null results are not surprising since the ACA deliberately aimed to not disrupt these other types of health insurance coverage.

\footnotetext{
${ }^{20}$ Sonier et al. (2013) discusses the potential for this "woodwork" or "welcome-mat" effect. Marton and Yelowitz (2015) highlight that non-participating eligibles may view themselves as "conditionally covered" and the individual mandate then compels such participation.
} 
Tables 3 and 4 only compute impacts of the ACA at the mean pre-treatment uninsured rate of 20.3 percent. This approach masks considerable heterogeneity in the law's effects since local area pre-treatment uninsured rates varied widely, ranging from 3 to 53 percent with a standard deviation of 7 percent. Figure 2 therefore shows how the predicted changes in coverage vary across this range of uninsured rates in both Medicaid expansion and non-expansion states. We see that for practically every type of coverage the larger the proportion of population uninsured in 2013 in the state, the larger the gain in coverage. The only exception is the "other source of coverage" category for the ACA without a Medicaid expansion, and this is highly statistically insignificant.

More specifically, the top left graph on figure 2 shows that the predicted impact of the full ACA on the probability of having any insurance coverage reached as high as 15.4 percentage points at the highest pre-treatment uninsured rate (53 percent) observed in our sample. In contrast, without the Medicaid expansion the maximum effect was only 7.8 percentage points. Not surprisingly, this difference in maximum impacts is due entirely to differences in the increases in Medicaid coverage. The "Medicaid coverage" graph predicts increases in Medicaid coverage that reach as high as 9.7 and 1.4 percentage points in Medicaid expansion and nonexpansion states, respectively.

In the cases of any private, employer provided, individually purchased and other coverage, the coverage effects may appear slightly different in Medicaid expansion versus nonexpansion states, but these differences are never statistically significant at any level of uninsurance. We therefore focus on the results for the full ACA, including the Medicaid expansion. At the highest uninsured rate of 53 percent, we estimate that the full ACA increased private 
coverage by 6.3 percentage points, increased ESI by 4.1 percentage points, increased individual coverage by 2.3 percentage points, and had no significant effect on other coverage.

\section{FALSIFICATION TESTS}

As discussed previously, identification of the parameters of interest in our models from section IV relies on two key assumptions. Conditional on the controls, if the ACA had not occurred 1) changes in insurance coverage in 2014 would not have been correlated with pretreatment uninsured rates, and 2) any differential changes in insurance coverage in 2014 between Medicaid expansion and non-expansion states would not have been correlated with pre-treatment uninsured rates. Of course, it is not possible to directly test these assumptions since we cannot observe the counterfactual. However, we can indirectly assess the likelihood of these assumptions holding by evaluating changes in the pre-treatment years. If "placebo" interventions during the pre-treatment period are associated with significant changes in coverage, this would suggest that significant changes may have also occurred in 2014 even in the absence of the ACA, in which case our main results cannot be given a causal interpretation.

We conduct these placebo analyses by running the baseline DDD model given by equation (2) using only the pre-treatment portion of the sample (2011-2013) and pre-dating the intervention. The first test defines 2011 to be a pre-treatment year and 2012-2013 to be posttreatment years, while the second defines 2011-2012 as pre-treatment years and 2013 as the post-

treatment year. Table 5 presents the results for the coefficients on $U N I N S U R E D_{a s} * P O S T_{t}$ and UNINSURED $D_{a s} * M E D I C A I D_{s} * P O S T_{t}$ from the DDD specification with the full set of controls. With twelve regressions and two coefficients of interest in each, there are a total of 24 falsification tests. We observe only one statistically significant result: UNINSURED $D_{a s} * P O S T_{t}$ in the regression for individually purchased coverage. In other words, $1 / 24$ tests, or 4.2 percent, 
yield significant "effects" at a 5 percent significance level, which is essentially what we would expect by chance even for true null hypotheses. In sum, these results provide reassurance about the validity of our model to estimate causal effects for the "true" ACA.

Another way we evaluate the assumption of common pre-treatment trends is with an event study model that interacts the treatment variables with the full set of year fixed effects, leaving 2013 as the base year. The regression takes the form

$$
\begin{gathered}
y_{\text {iast }}=\theta_{0}+\theta_{1}\left(\text { UNINSURED }_{a s} * Y 2011_{t}\right)+\theta_{2}\left(\text { UNINSURED }_{a s} * Y 2012_{t}\right)+ \\
\theta_{3}\left(\text { UNINSURED }_{a s} * Y 2014_{t}\right)+\theta_{4}\left(\text { MEDICAID }_{s} * Y 2011_{t}\right)+\theta_{5}\left(\text { MEDICAID }_{s} * Y 2012_{t}\right)+ \\
\theta_{6}\left(\text { MEDICAID }_{s} * Y 2014_{t}\right)+\theta_{7}\left(\text { UNINSURED }_{a s} * \text { MEDICAID }_{s} * Y 2011_{t}\right)+ \\
\theta_{8}\left(\text { UNINSURED }_{a s} * \text { MEDICAID }_{s} * Y 2012_{t}\right)+\theta_{9}\left(\text { UNINSURED }_{a s} * \text { MEDICAID }_{s} *\right. \\
\left.Y 2014_{t}\right)+\boldsymbol{\theta}_{\mathbf{1 0}} \boldsymbol{X}_{\text {iast }}+\tau_{\tau}+\alpha_{a s}+\varepsilon_{\text {iast }}
\end{gathered}
$$

where $Y 2011_{t}, Y 2012_{t}$, and $Y 2014_{t}$ are indicators for whether year $t$ is 2011, 2012, and 2014, respectively. The falsification tests are whether the coefficients on the "treatment" variables in the pre-treatment years $\left(\theta_{1}, \theta_{2}, \theta_{7}, \theta_{8}\right)$ are equal to zero.

Table 6 presents the event study results for each of the six outcomes using the full set of controls. The top panel presents the coefficient estimates of interest. There are again 24 falsification tests (one for each parameter of interest related to 2011 and 2012) and only one significant result at the 5 percent level. The bottom panel of the table uses the results from the 2014 interaction terms to compute the effects of the ACA without the Medicaid expansion, the Medicaid expansion, and the full ACA. The estimated impacts of the "true" ACA, shown in the bottom panel, are very similar to those from tables 3 and 4 . 


\section{SUBSAMPLE ANALYSES}

Our baseline DDD model described in equation (2) does not allow our estimates of the impact of the ACA to vary by any of the demographic characteristics contained in $\boldsymbol{X}_{\text {iast }}$, such as income, race/ethnicity, age, gender, or marital status. Because we expect the impact of the ACA to differ in a meaningful way across demographic groups, we estimate a series of subsample regressions in order to assess the magnitude of these differences. In general, we expect that demographic groups with the highest pre-treatment uninsured rates generate the largest gains in coverage in 2014. For example, table 1 shows that non-whites makes up 36.8 percent of our sample, but 44.2 percent of those whose baseline uninsured rate is above the median. Thus, everything else equal, we would expect larger gains in coverage for non-whites as compared to non-Hispanic whites. Similarly, pre-ACA uninsured rates were highest for low-income individuals, young adults, men, and unmarried individuals. Additionally, the design of the subsidies for exchange coverage and the fact that several states opted out of the Medicaid expansion generates the potential for further differential gains in coverage across certain demographic characteristics, such as income and age.

For each subsample, we re-compute the pre-treatment uninsured rate using only individuals within that particular subsample. Since each subsample must therefore contain enough respondents in the 2013 to precisely compute uninsured rates at the local level, we are constrained to a maximum of two or three subsamples for each of our demographic stratifications. For instance, we might ideally prefer to stratify our sample into four race/ethnicity subsamples - non-Hispanic white, non-Hispanic black, Hispanic, and other - but some of our local areas have such a low proportion of blacks or Hispanics that the 2013 ACS sample size 
from those areas is insufficient to credibly compute pre-treatment uninsured rates. Consequently, we only separate the sample into non-Hispanic whites versus others.

Table 7 presents the results of a stratification of our sample into three groups based on income: those under 138 percent FPL, those between 138 and 400 percent FPL, and those above 400 percent FPL. As discussed in Courtemanche et al. (2016), non-elderly adults below 100 percent FPL are eligible for Medicaid in expansion states, but not in states that opted out of the expansion. Those with income between 100 and 137 percent FPL are also eligible for Medicaid in expansion states and for subsidized exchange coverage in non-expansion states. ${ }^{21}$ In all states, those with incomes between 138 and 400 of the FPL are eligible for subsidized exchange coverage with a sliding-scale subsidy. Finally, those with incomes above 400 percent FPL are not eligible for a subsidy, but do face the individual mandate. ${ }^{22}$

A potential complication with stratifying by income is that income could be endogenous to the ACA. For this reason, Kaestner et al. (2015) defined the sample based on education levels rather than income levels in their analysis of the effects of the ACA's Medicaid expansion on low socio-economic status individuals. However, our interpretation of the recent literature is that any such selection issues are likely to be minor. Kaestner et al. (2015) found no evidence that the ACA Medicaid expansion affected employment or work hours, while results from the randomized Oregon experiment suggest no effect of Medicaid on employment or earnings (Baicker et al., 2014). Early evidence on the ACA dependent coverage mandate suggested a reduction in labor supply among young adults after becoming eligible for parental coverage (Akosa Antwi et al., 2013), but this result has been challenged on methodological grounds

\footnotetext{
${ }^{21}$ We did not further separate those under 100 percent FPL from those between 100 and 138 percent due to insufficient numbers of pre-treatment individuals in the 100 to 138 FPL range in some local areas.

${ }^{22}$ Note that our income stratifications might not exactly match to these eligibility cutoffs, both because of reporting error and the fact that we observe gross income whereas eligibility is based on modified adjusted gross income.
} 
(Slusky, 2015). Nonetheless, we have verified that if we stratify by education rather than income (e.g. high school education or less, some college, and college degree or more), we observe the same general pattern of results. These results are available upon request.

Our results reported in table 7 suggest that, in expansion states, the largest effects on insurance coverage occurred among those with incomes below 138 percent FPL. Full implementation of the ACA is predicted to increase coverage by 10.3 percentage points for this group, from a base of 61 percent. This can be primarily attributed to an increase in Medicaid coverage of 8.8 percentage points. As mentioned, individuals (not already eligible) within this income range in expansion states were made newly eligible for free Medicaid coverage.

Another interesting result for the low-income subsample is that, in contrast to the fullsample results, we find some evidence of crowd out: the Medicaid expansion reduced private coverage by 1.8 percentage points, split roughly evenly between ESI and individually purchased coverage. This is a non-trivial magnitude, as it represents 23 percent of the 8 percentage point increase in Medicaid coverage from the Medicaid expansion. Kaestner et al. (2015) estimated a very similar Medicaid crowd-out rate in their sample of adults with relatively low education levels. They found a 4 percentage point increase in Medicaid coverage and a 1 percentage point reduction in private coverage, for a crowd-out rate of 25 percent. Nonetheless, both our estimate and that of Kaestner et al. (2015) are statistically insignificant, so these results should not be taken as definitive evidence of crowd-out.

Among those with incomes between 138 and 400 percent FPL, full implementation of the ACA is predicted to increase coverage by 6.3 percentage points (from a base of 76.3 percent). An increase in private coverage appears to be the main driver of coverage gains for this group, as full implementation of the ACA increased private coverage by 5 percentage points, accompanied 
by a smaller increase in Medicaid coverage (1.5 percentage points). This increase in private coverage comes from both gains in the take up of employer-provided coverage, perhaps encouraged by the individual mandate, and new access to subsidized exchange coverage. Interestingly, in states that did not expand Medicaid, overall coverage gains among those in the 138 to 400 percent range (4.6 percentage points) are essentially the same as those among individuals below 138 percent (4.8 percentage points).

In both expansion and non-expansion states, by far the smallest gains in coverage are among those with incomes above 400 percent FPL. We estimate that full implementation of the ACA increases coverage by 1.6 percentage points (from a base of 93.3 percent). The majority of this effect comes from an increase in private insurance coverage (1.1 percentage points).

Next we stratify the sample by age into three categories, those $18-34$, those $35-49$, and those 50-64. Table 8 reports pre-treatment uninsured rates that decline with age, falling from 25.7 percent for the youngest group to 14.5 percent for the oldest group. The reason for being uninsured likely differs by age, with the relatively young possibly viewing health insurance as an unnecessary expense given their good overall health, while older individuals may have trouble finding affordable coverage due to poor health. Given the individual mandate, both groups may find exchange coverage attractive for different reasons, such as the potential for a premium subsidy (benefiting the young) and the presence of a more diverse risk pool (benefiting the old). Table 8 shows that the largest gains in coverage are for the 18-34 year old group. Full implementation of the ACA is predicted to increase coverage by 7.3 percentage points among this group, by 4.9 percentage points among 35-49 year olds, and by 5.3 percentage points among 50-64 year olds. For all age groups, increases in Medicaid coverage account for more than half of 
the increase in coverage. In addition, the full effect of the ACA on individually purchased insurance for 18-34 and 50-64 year olds is larger than for 35-49 year olds, as predicted.

Table 9 reports results based on a stratification of our sample by race/ethnicity. We group individuals into two categories: non-Hispanic white or non-white. The pre-treatment uninsured rate among non-whites (30.3 percent) is roughly twice that for non-Hispanic whites (14.4 percent), so we expect bigger gains in coverage for non-whites. Our results support this hypothesis, as non-whites experience an estimated increase in coverage of 7.9 percentage points, whereas non-Hispanic whites experience an estimated 5.7 percentage point increase in coverage from full ACA implementation. For both groups the increase in Medicaid coverage was larger than the increase in private insurance coverage. ${ }^{23}$

Table 10 presents results stratifying by marital status. Full implementation of the ACA increased coverage by 8.3 percentage points (from a base of 73.3 percent) among the unmarried compared to just 4.1 percentage points (from a base of 85.9 percent) among the married. Among the married, full implementation of the ACA is predicted to increase Medicaid coverage by 2.4 percentage points and private insurance coverage by 1.9 percentage points (roughly split between increases in individually purchased insurance and ESI). Among the unmarried, full implementation of the ACA is predicted to increase Medicaid coverage by 5.5 percentage points and private insurance coverage by 3.0 percentage points (with the majority of this increase coming from gains in ESI).

Finally, we stratified the sample by gender but did not observe evidence of any noteworthy differences in the effects of the ACA between men and women. We therefore do not discuss the results further and relegate them to table A6 of the online appendix.

\footnotetext{
${ }^{23}$ For non-Hispanic whites, the increase in Medicaid coverage from full ACA implementation is 4.9 percentage points and the increase in private coverage is 1.6 percentage points. For non-whites, these values are 4.3 and 3.4 percentage points, respectively.
} 


\section{DISCUSSION}

Overall, our results suggest that, at the average local area pre-treatment uninsured rate, the Medicaid expansion component of the ACA increased coverage by 2.9 percentage points in 2014, while the implementation of the other components of the ACA increased coverage by 3.0 percentage points. Thus fully implementing all of the 2014 provisions of the ACA is predicted to increase coverage by 5.9 percentage points. Since the 2013 non-elderly uninsured rate was 20.3 percent, our estimates imply that if the ACA had been fully implemented in all states, the nonelderly uninsured rate would have fallen by 29 percent. In contrast, the actual effect of the ACA - computed by taking the population-weighted average of the effects in Medicaid expansion and non-expansion states - has been just 22.55 percent. $^{24}$

These results for overall coverage alone extend the literature in several important ways. First, a simple comparison of the difference in coverage gains between Medicaid expansion and non-expansion states reported in the descriptive literature (Long et al., 2014; Smith and Medalia, 2015; Courtemanche et al., 2016) suggests merely an additional 1-1.5 percentage point coverage gain in expansion states in 2014. Our results suggest that the causal impact of the Medicaid expansion at the mean pre-treatment uninsured rate is roughly two to three times as large as these descriptive estimates. This highlights the value of our approach, which allows us to control for observed and unobserved confounders. An accurate estimate of the share of the increase in coverage that can be attributed to the Medicaid expansion is information of crucial importance to state policymakers considering such an expansion.

Second, our use of an alternative identification strategy allows us to separately estimate the causal impact of the Medicaid expansion and the casual impact of the other components of

\footnotetext{
${ }^{24} 54.37$ percent of our sample lives in states that expanded Medicaid while 45.63 percent lived in non-expansion states. The weighted average effect is therefore 5.9 percentage points $* 54.37$ percent +3.0 percentage points $*$ 45.63 percent, which comes to 4.58 percentage points, or 22.55 percent of the 20.3 percent baseline uninsured rate.
} 
the ACA. Our estimate of the impact of the Medicaid expansion (2.9 percentage points) on any form of coverage among non-elderly adults is similar to Kaestner et al.'s (2015) estimate of 3 percentage points, though their sample only included adults with no further than a high school education. ${ }^{25}$ However, their approach does not allow them to estimate the causal impact of the other components of the ACA, which we estimate to be roughly equal in magnitude (3.0 percentage points) to the impact of the Medicaid expansion on any form of coverage.

Third, we evaluate the impact of the ACA on a relatively detailed set of sources of insurance. Two of the descriptive studies we described, Long et al. (2014) and Smith and Medalia (2015), do not differentiate between different sources of coverage at all, while Kaestner et al. (2015) only considers two sources of coverage, Medicaid and private coverage. We differentiate between private coverage coming from the employer-provided group market and that coming from the non-group market (such as exchange coverage) and discover that a slightly larger share of the increase in private coverage resulting from the ACA is attributable to ESI as opposed to individually purchased plans. This is a surprising and interesting result for two reasons. First, we might have expected a smaller effect on ESI, since the ACA deliberately did not try to alter the employer-provided market, and the employer mandate had not yet taken effect in 2014. One possible explanation is that the individual mandate may have increased take-up of ESI, either among employees or their spouse or dependents. Second, we might have expected a larger effect on individually purchased insurance since 8 million people enrolled in the exchanges in 2014 (HHS, 2014). Multiplying our results (1.1 percentage point increase in private coverage) by the number of US residents (199 million; Colby and Ortman, 2015) in the 18-64

\footnotetext{
${ }^{25}$ In addition, our results from table 4 suggest that the Medicaid expansion increased Medicaid enrollment by 3.2 percentage points at the mean pre-treatment uninsured rate. This result is slightly lower than Kaestner et al.'s estimated 4 percentage point effect of the Medicaid expansion on Medicaid coverage among individuals with low education levels.
} 
age range in 2014 and dividing by 8 million, we compute that only 27.36 percent of people who purchased a plan through the exchanges were newly covered. In other words, our results imply that most individuals in the exchanges in 2014 already had some form of insurance in 2013. This can be considered a form of crowd-out since most exchange plans were subsidized. Of course, even if individuals participating in the exchanges already had some sort of insurance prior to the ACA taking effect, the quality of their coverage may have improved with regard to deductibles, copayments, and range of services covered.

Another contribution of our paper is to present several new results related to heterogeneity in the ACA's impacts. We found that the coverage gains from the full ACA were largest for those with incomes below the Medicaid eligibility threshold, non-whites, young adults, and unmarried individuals. These results have important implications for disparities. For instance, our estimates imply that the fully implemented ACA reduced the difference in uninsured rates between the lowest (under 138 percent FPL) and highest (over 400 percent FPL) income groups by 8.7 percentage points, or 27 percent. ${ }^{26}$ However, the ACA without the Medicaid expansion only lowered this gap by 11 percent. $^{27}$ Similarly, the fully implemented ACA lowered the coverage disparity between whites and non-whites by 2.2 percentage points, or 14 percent, whereas the ACA without the Medicaid expansion actually increased this disparity. ${ }^{28}$

\footnotetext{
${ }^{26}$ These calculations are based on the results from table 7. The 2013 uninsured rates for the low and high income groups were 39 percent and 6.7 percent, respectively, for a difference of 32.3 percentage points. Subtracting the estimated effects of the full ACA for the two groups (10.3 and 1.6 percentage points) reduces this difference to 23.6 percentage points. Therefore, the full ACA reduced the disparity by 8.7 percentage points, or 27 percent of 32.3 . ${ }^{27}$ This calculation is based on the same process discussed in the previous footnote, but replacing the 10.3 and 1.6 percentage point effects from the full ACA with the 4.8 and 1.3 percentage point effects among the low and high income groups from the ACA without the Medicaid expansion.

${ }^{28}$ These calculations are based on the results from table 9. The 2013 uninsured rates for non-whites and whites were 30.3 percent and 14.4 percent, for a difference of 15.9 percentage points. Subtracting the estimated effects of the full ACA for the two groups reduces this difference to 13.7 percentage points, for a 2.2 percentage point reduction, which represents 14 percent of 15.9. The claim that the ACA without the Medicaid expansion increased the disparity is based on the finding from table 8 that the non-Medicaid portions of the ACA led to larger coverage gains among whites than non-whites.
} 
Our income stratifications also contribute to the debate surrounding the potential for Medicaid to crowd-out private insurance among low-income individuals. We estimate that, among adults with incomes below the ACA's Medicaid eligibility threshold, the Medicaid expansion increased Medicaid coverage by 8 percentage points while decreasing private coverage by 1.8 percentage points, for a crowd out rate of 23 percent. This is very similar to the 25 percent crowd-out rate obtained by Kaestner et al. (2015) in their sample of low-education adults. While these magnitudes seem sizeable, the effects in both studies are statistically insignificant and therefore should be deemed inconclusive.

Our final contribution is methodological: our identification strategy for the non-Medicaid expansion portion of the ACA can potentially be used in future research to identify the impacts of the ACA on other outcomes such as health care utilization, health, and personal finances. It should be noted, though, that identifying off of pre-treatment uninsured rates implicitly assumes that the extensive margin of coverage is the only pathway through which the ACA affects the outcome. We find this assumption reasonable in the context of health insurance coverage, but it may be more problematic for outcomes such as health care utilization and health. In these cases, other mechanisms such as the quality of coverage (intensive margin) and the income redistribution caused by the ACA's subsidies and community rating might be expected to play a role as well, so the identification strategy would need to be adjusted accordingly.

An obvious caveat of our work is that, due to data availability, we only estimate the effects in the first year of full ACA implementation, 2014. As future waves of the ACS become available, it would be worthwhile to revisit our estimates. The number of people who purchased a plan through the ACA's exchanges rose from 8 million in 2014 to 8.8 million in 2015 , and 12.7 million have selected a marketplace plan in 2016. The impacts on individually purchased 
coverage and overall coverage may therefore have become stronger over time. ${ }^{29}$ Additionally, the employer mandate had not yet taken effect in $2014 .{ }^{30}$ Nonetheless, our paper provides important evidence about the ACA's early effects that can help guide ongoing policy debates.

\section{REFERENCES}

Aizer, Anna. (2007). Public Health Insurance, Program Take-up, and Child Health. The Review of Economics and Statistics, 89 (3), 400-15.

Akosa Antwi, Yaa, Asako S. Moriya, and Kosali Simon. (2013). Effects of Federal Policy to Insure Young Adults: Evidence from the 2010 Affordable Care Act Dependent Coverage Mandate. American Economic Journal: Economic Policy, 5, 1-28.

Baicker, Katherine, Amy Finkelstein, Jae Song, and Sarah Taubman (2014). The Impact of Medicaid on Labor Market Activity and Program Participation: Evidence from the Oregon Health Insurance Experiment. American Economic Review: Papers and Proceedings, 104(5), 322-328.

Barbaresco, Silvia, Charles Courtemanche, and Yanling Qi. (2015). Impacts of the Affordable Care Act Dependent Coverage Provision on Health-related Outcomes of Young Adults. Journal of Health Economics, 40, 54-68.

Buchmueller, Thomas, John C. Ham, Lara D. Shore-Sheppard. (2015). Medicaid. Means-Tested Transfer Programs in the United States, II. Robert Moffitt, editor. Forthcoming.

Busch, Susan H. and Noelia Duchovny. (2005). Family Coverage Expansions: Impact on Insurance Coverage and Health Care Utilization of Parents. Journal of Health Economics, 24 (5), 876-90.

Colby, Sandra L. and Jennifer M. Ortman, U.S. Census Bureau, Current Population Reports, P25-1143, Projections of the Size and Composition of the U.S. Population: 2014 to 2060, U.S. Government Printing Office, Washington, DC, 2015.

Courtemanche, Charles and Daniela Zapata. (2014). Does Universal Coverage Improve Health? The Massachusetts Experience. Journal of Policy Analysis and Management, 33 (1), 36-69.

\footnotetext{
${ }^{29}$ For more information on exchange enrollment, see the following Kaiser Family Foundation websites: http://kff.org/health-reform/state-indicator/marketplace-enrollment-as-a-share-of-the-potential-marketplacepopulation-2015/, http://kff.org/health-reform/state-indicator/state-marketplace-statistics/

${ }^{30}$ See the Kaiser Family Foundation ACA implementation timeline for more information: http://kff.org/interactive/implementation-timeline/
} 
Courtemanche, Charles, James Marton, and Aaron Yelowitz (2016). Who Gained Insurance Coverage in 2014, the First Year of Full ACA Implementation? Health Economics, forthcoming

Cutler, David M and Jonathan Gruber. (1996). Does Public Insurance Crowd out Private Insurance? The Quarterly Journal of Economics, 111 (2), 391-430.

Finkelstein, Amy. (2007). The Aggregate Effects of Health Insurance: Evidence from the Introduction of Medicare. The Quarterly Journal of Economics, 122 (1), 1-37.

Gruber, Jonathan. (2011). The Impacts of the Affordable Care Act: How Reasonable Are the Projections? National Bureau of Economic Research Working Paper 17168. Cambridge, MA: National Bureau of Economic Research.

Hamersma, Sarah and Matthew Kim. 2013. Participation and Crowd Out: Assessing the Effects of Parental Medicaid Expansions. Journal of Health Economics, 32 (1), 160-71.

Kaiser Family Foundation. State decisions on health insurance marketplaces and the Medicaid expansion, 2014.

Kenney, Genevieve, R. Andrew Allison, Julia F. Costich, James Marton, and Joshua McFeeters. (2006). Effects of Premium Increases on Enrollment in SCHIP: Findings from Three States. INQUIRY: The Journal of Health Care Organization, Provision, and Financing, 43 (4), 378-92.

Kowalski, Amanda. (2014).The Early Impact of the Affordable Care Act State-by-State. National Bureau of Economic Research Working Paper 20597. Cambridge, MA: National Bureau of Economic Research.

Long, Sharon K., Michael Karpman, Adele Shartzer, Douglas Wissoker, Genevieve M. Kenney, Stephen Zucherman, Nathanial Anderson, \& Katherine Hempstead. (2014). Taking Stock: Health Insurance Coverage under the ACA as of September 2014. Washington, DC: Urban Institute.

Long, Sharon K., Karen Stockley, \& Alshadye Yemane. (2009). Another Look at the Impacts of Health Reform in Massachusetts: Evidence using New Data and a Stronger Model. American Economic Review, Papers \& Proceedings, 99 (2), 508-511.

Marton, James. (2007). The Impact of the Introduction of Premiums into a SCHIP Program. Journal of Policy Analysis and Management, 26 (2), 237-55.

Marton, James, Patricia G. Ketsche, Angela Snyder, E. Kathleen Adams, and Mei Zhou. (2015). Estimating Premium Sensitivity for Children's Public Health Insurance Coverage: Selection but No Death Spiral. Health Services Research, 50 (2), 579-598.

Marton, James, Angela Snyder, and Mei Zhou. (2016). Enhanced Citizenship Verification and Children's Medicaid Coverage. Economic Inquiry, forthcoming.

Marton, James and Aaron Yelowitz. (2015). Health Insurance Generosity and Conditional 
Coverage: Evidence from Medicaid Managed Care in Kentucky. Southern Economic Journal, 82(2), 535-555.

Marton, James, Aaron Yelowitz, and Jeffery C. Talbert. (2014). A Tale of Two Cities? The Heterogeneous Impact of Medicaid Managed Care. Journal of Health Economics, 36, 47-68.

Marton, James, Aaron Yelowitz, Jeffery C. Talbert, and Meredith Shores. (2016). Does Medicaid Managed Care Help Equalize Racial and Ethnic Disparities in Utilization? Health Services Research, forthcoming.

Medicaid and CHIP Payment and Access Commission. (2015). Expanding Medicaid to the New Adult Group through Section 1115 Waivers. MACPAC Fact Sheet.

Miller, Sara. (2012). The Effect of Insurance on Emergency Room Visits: An Analysis of the 2006 Massachusetts Health Reform. Journal of Public Economics, 96, 893-908.

Mishra, Abhay N., Patricia Ketsche, James Marton, Angela Snyder, and Susan McLaren. (2014). Examining the Potential of Information Technology to Improve Public Insurance Application Processes: Enrollee Assessments from a Concurrent Mixed Method Analysis. Journal of the American Medical Informatics Association, 21 (6), 1045-1052.

Slusky, David (forthcoming). Significant Placebo Results in Difference-in-Differences Analysis: The Case of the ACA's Parental Mandate. Eastern Economic Journal.

Smith, Jessica C. and Carla Medalia, U.S. Census Bureau, Current Population Reports, P60-250, Health Insurance Coverage in the United States: 2013, U.S. Government Printing Office, Washington, DC, 2014.

Smith, Jessica C. and Carla Medalia, U.S. Census Bureau, Current Population Reports, P60-253, Health Insurance Coverage in the United States: 2014, U.S. Government Printing Office, Washington, DC, 2015.

Sommers, Benjamin D. (2010). Targeting in Medicaid: The Costs and Enrollment Effects of Medicaid's Citizenship Documentation Requirement. Journal of Public Economics, 94 (1-2), 174-82.

Sommers, Benjamin D., Thomas Buchmueller, Decker, S.L., Carey, C., Richard Kronick. (2013). The Affordable Care Act has led to Significant Gains in Health Insurance and Access to Care for Young Adults. Health Affairs 32, 165-174.

Sonier, Julie, Michel H. Boudreaux, Lynn A. Blewett. (2013). Medicaid "Welcome-Mat" Effect of Affordable Care Act Implementation Could be Substantial. Health Affairs 32: 71319-71325.

Swartz, Katherine. (1986). Interpreting the Estimates from Four National Surveys of the Number of People without Health Insurance. Journal of Economic and Social Measurement, 14 (3), 233242. 
U.S. Department of Health and Human Services, Office of the Assistant Secretary for Planning and Evaluation. (2014). Health Insurance Marketplace: Summary Enrollment Report for the Initial Annual Open Enrollment Period. ASPE Issue Brief. Washington, DC. [HHS, 2014]

Wolfe, Barbara and Scott Scrivner. (2005). The Devil May Be in the Details: How the Characteristics of SCHIP Programs Affect Take-Up. Journal of Policy Analysis and Management, 24 (3), 499-522.

Yelowitz, Aaron, \& Michael F. Cannon. (2010). The Massachusetts Health Plan Much Pain, Little Gain. Policy Analysis, 657, 1-16. 
Figure 1 - Changes in Insurance Coverage over Time by State Medicaid Expansion Status and Pre-Treatment Uninsured Rate
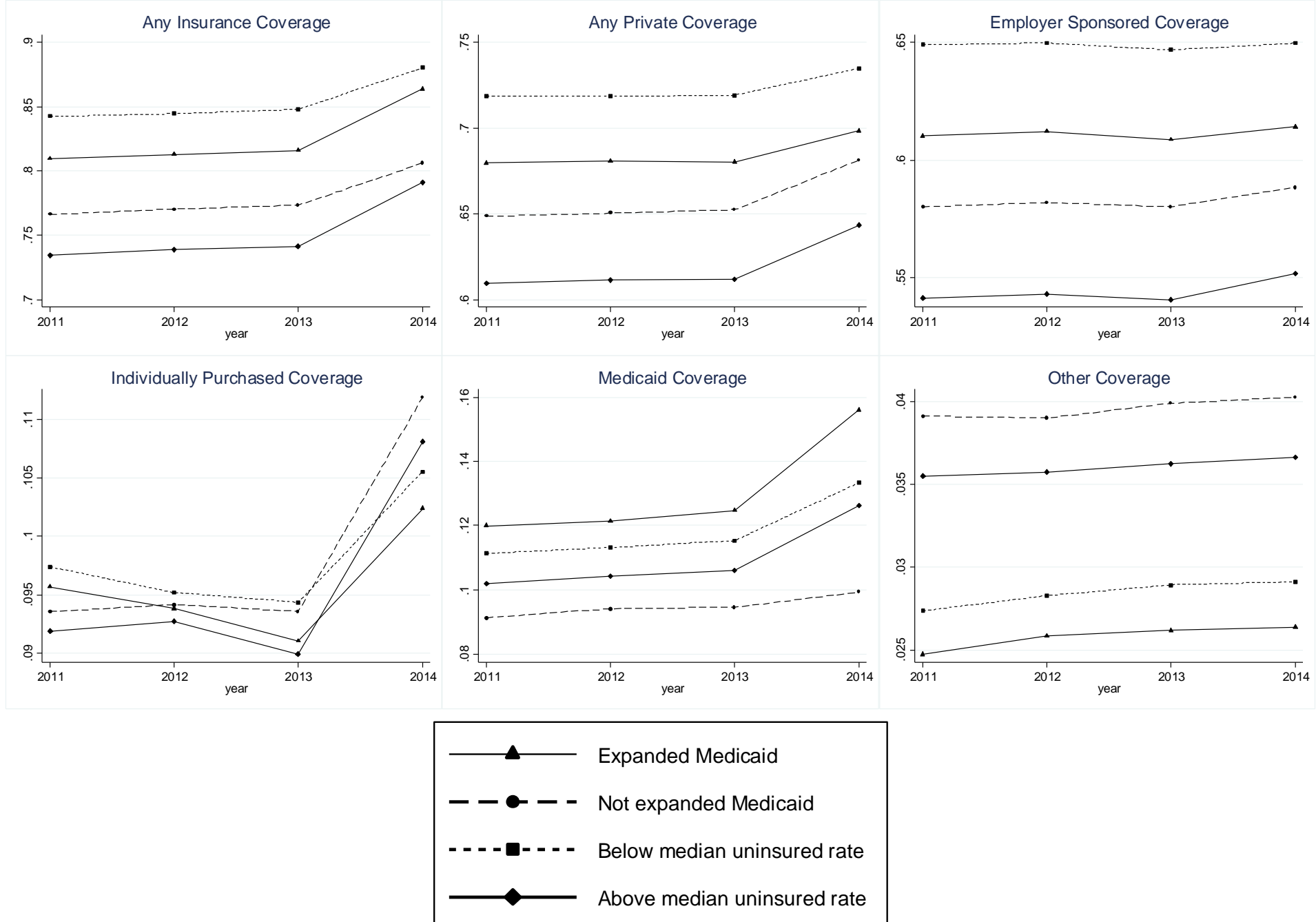
Figure 2 - ACA Effect on Insurance Coverage at Pre-Treatment Uninsured Rate
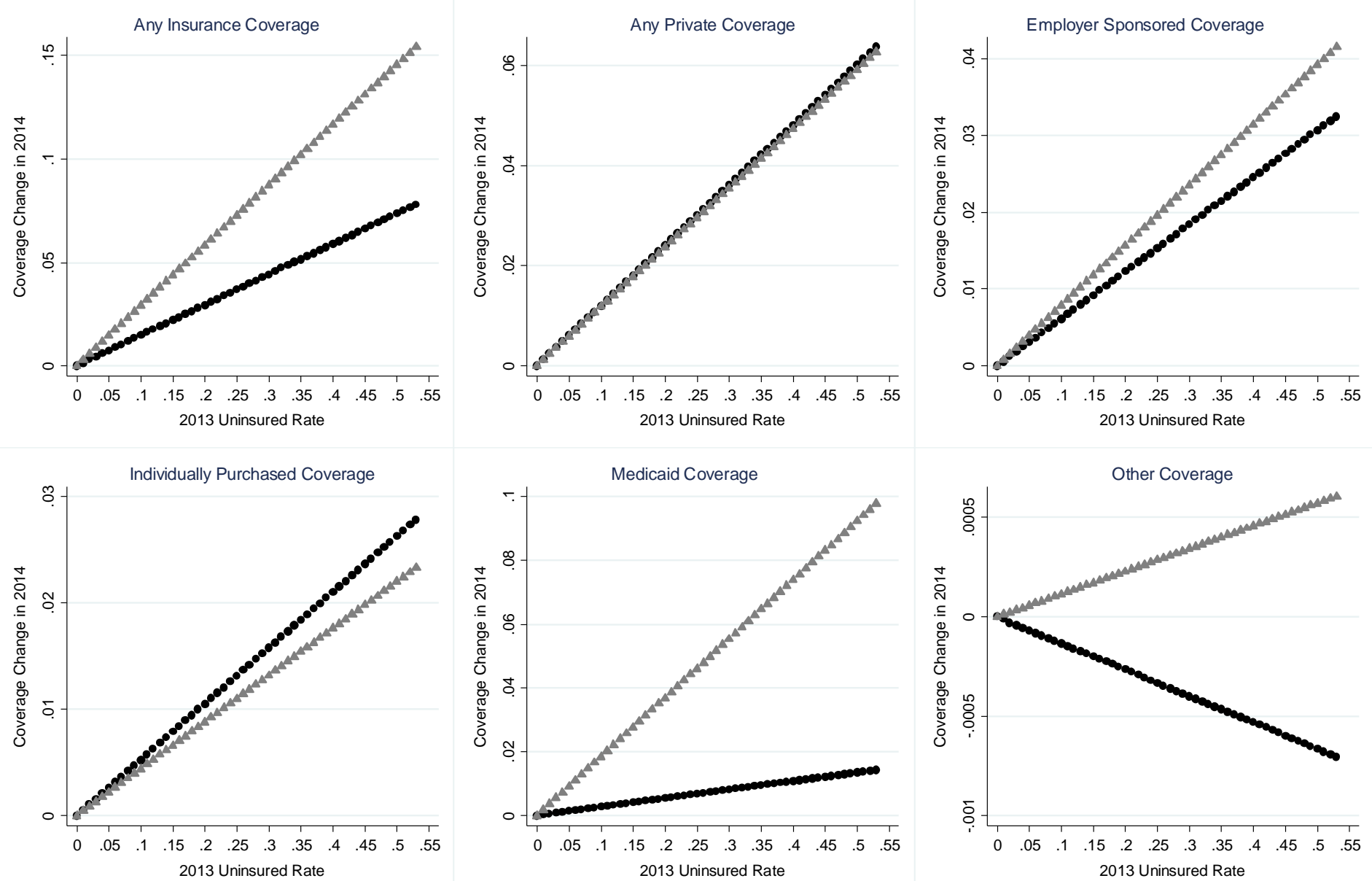

$\triangle$ Full ACA - ACA Without Medicaid Expansion 
Table 1 - Pre-Treatment Means and Standard Deviations of Dependent Variables by State Medicaid Expansion Status and Pre-Treatment Uninsured Rate

\begin{tabular}{lccccc}
\hline & $\begin{array}{c}\text { Full } \\
\text { Sample }\end{array}$ & $\begin{array}{c}\text { Medicaid } \\
\text { Expansion } \\
\text { States }\end{array}$ & $\begin{array}{c}\text { Medicaid } \\
\text { Non- } \\
\text { Expansion } \\
\text { States }\end{array}$ & $\begin{array}{c}\text { Below } \\
\text { Median } \\
\text { Baseline } \\
\text { Uninsured } \\
\text { Rate }\end{array}$ & $\begin{array}{c}\text { Above } \\
\text { Median } \\
\text { Baseline } \\
\text { Uninsured } \\
\text { Rate }\end{array}$ \\
\hline Any insurance coverage & 0.804 & 0.825 & 0.779 & 0.854 & 0.752 \\
Any private & $(0.396)$ & $(0.379)$ & $(0.414)$ & $(0.353)$ & $(0.432)$ \\
Employer-sponsored & 0.672 & 0.684 & 0.658 & 0.723 & 0.619 \\
& $(0.459)$ & $(0.464)$ & $(0.474)$ & $(0.448)$ & $(0.486)$ \\
Individually purchased & 0.598 & 0.611 & 0.582 & 0.649 & 0.544 \\
& $(0.490)$ & $(0.487)$ & $(0.493)$ & $(0.477)$ & $(0.498)$ \\
Medicaid & 0.096 & 0.095 & 0.098 & 0.098 & 0.096 \\
& $(0.295)$ & $(0.294)$ & $(0.297)$ & $(0.297)$ & $(0.294)$ \\
Other & 0.114 & 0.130 & 0.094 & 0.118 & 0.110 \\
& $(0.318)$ & $(0.336)$ & $(0.293)$ & $(0.323)$ & $(0.313)$ \\
& 0.032 & 0.025 & 0.039 & 0.028 & 0.036 \\
& $(0.176)$ & $(0.158)$ & $(0.194)$ & $(0.160)$ & $(0.186)$ \\
\hline
\end{tabular}

Notes: Standard deviation in parentheses. 
Table 2 - Pre-Treatment Summary Statistics for Control Variables

\begin{tabular}{|c|c|c|c|c|c|}
\hline & $\begin{array}{c}\text { Full } \\
\text { Sample }\end{array}$ & $\begin{array}{c}\text { Medicaid } \\
\text { Expansion } \\
\text { States }\end{array}$ & $\begin{array}{l}\text { Medicaid } \\
\text { Non- } \\
\text { Expansion } \\
\text { States }\end{array}$ & $\begin{array}{c}\text { Below } \\
\text { Median } \\
\text { Baseline } \\
\text { Uninsured } \\
\text { Rate }\end{array}$ & $\begin{array}{c}\text { Above } \\
\text { Median } \\
\text { Baseline } \\
\text { Uninsured } \\
\text { Rate }\end{array}$ \\
\hline \multicolumn{6}{|l|}{ Demographic controls } \\
\hline \multicolumn{6}{|c|}{ Age dummies (18-24 is omitted base category) } \\
\hline Age $25-29$ & $\begin{array}{c}0.108 \\
(0.311)\end{array}$ & $\begin{array}{c}0.109 \\
(0.312)\end{array}$ & $\begin{array}{c}0.107 \\
(0.309)\end{array}$ & $\begin{array}{c}0.109 \\
(0.311)\end{array}$ & $\begin{array}{c}0.109 \\
(0.312)\end{array}$ \\
\hline Age $30-34$ & $\begin{array}{c}0.107 \\
(0.309)\end{array}$ & $\begin{array}{c}0.107 \\
(0.309)\end{array}$ & $\begin{array}{c}0.106 \\
(0.308)\end{array}$ & $\begin{array}{c}0.106 \\
(0.308)\end{array}$ & $\begin{array}{c}0.108 \\
(0.310)\end{array}$ \\
\hline Age $35-39$ & $\begin{array}{c}0.101 \\
(0.302)\end{array}$ & $\begin{array}{c}0.101 \\
(0.301)\end{array}$ & $\begin{array}{c}0.102 \\
(0.302)\end{array}$ & $\begin{array}{c}0.100 \\
(0.300)\end{array}$ & $\begin{array}{c}0.104 \\
(0.305)\end{array}$ \\
\hline Age $40-44$ & $\begin{array}{c}0.108 \\
(0.310)\end{array}$ & $\begin{array}{c}0.108 \\
(0.310)\end{array}$ & $\begin{array}{c}0.108 \\
(0.310)\end{array}$ & $\begin{array}{c}0.108 \\
(0.309)\end{array}$ & $\begin{array}{c}0.109 \\
(0.311)\end{array}$ \\
\hline Age $45-49$ & $\begin{array}{c}0.110 \\
(0.313)\end{array}$ & $\begin{array}{c}0.110 \\
(0.313)\end{array}$ & $\begin{array}{c}0.109 \\
(0.312)\end{array}$ & $\begin{array}{c}0.112 \\
(0.315)\end{array}$ & $\begin{array}{c}0.109 \\
(0.311)\end{array}$ \\
\hline Age $50-54$ & $\begin{array}{c}0.115 \\
(0.319)\end{array}$ & $\begin{array}{c}0.116 \\
(0.320)\end{array}$ & $\begin{array}{c}0.115 \\
(0.319)\end{array}$ & $\begin{array}{c}0.119 \\
(0.324)\end{array}$ & $\begin{array}{c}0.113 \\
(0.316)\end{array}$ \\
\hline Age $55-59$ & $\begin{array}{c}0.107 \\
(0.309)\end{array}$ & $\begin{array}{c}0.107 \\
(0.309)\end{array}$ & $\begin{array}{c}0.107 \\
(0.309)\end{array}$ & $\begin{array}{c}0.110 \\
(0.313)\end{array}$ & $\begin{array}{c}0.104 \\
(0.306)\end{array}$ \\
\hline Age $60-64$ & $\begin{array}{c}0.094 \\
(0.292)\end{array}$ & $\begin{array}{c}0.093 \\
(0.291)\end{array}$ & $\begin{array}{c}0.094 \\
(0.292)\end{array}$ & $\begin{array}{c}0.095 \\
(0.294)\end{array}$ & $\begin{array}{c}0.093 \\
(0.290)\end{array}$ \\
\hline Female & $\begin{array}{c}0.508 \\
(0.499)\end{array}$ & $\begin{array}{c}0.507 \\
(0.499)\end{array}$ & $\begin{array}{c}0.510 \\
(0.499)\end{array}$ & $\begin{array}{c}0.509 \\
(0.500)\end{array}$ & $\begin{array}{c}0.509 \\
(0.499)\end{array}$ \\
\hline \multicolumn{6}{|c|}{ Race/ethnicity dummies (non-Hispanic white is omitted base category) } \\
\hline Non-Hispanic black & $\begin{array}{c}0.122 \\
(0.327)\end{array}$ & $\begin{array}{c}0.094 \\
(0.292)\end{array}$ & $\begin{array}{c}0.154 \\
(0.361)\end{array}$ & $\begin{array}{c}0.114 \\
(0.317)\end{array}$ & $\begin{array}{c}0.131 \\
(0.338)\end{array}$ \\
\hline Hispanic & $\begin{array}{c}0.166 \\
(0.372)\end{array}$ & $\begin{array}{c}0.184 \\
(0.388)\end{array}$ & $\begin{array}{c}0.144 \\
(0.351)\end{array}$ & $\begin{array}{c}0.101 \\
(0.300)\end{array}$ & $\begin{array}{c}0.236 \\
(0.425)\end{array}$ \\
\hline Other & $\begin{array}{c}0.080 \\
(0.272)\end{array}$ & $\begin{array}{c}0.104 \\
(0.305)\end{array}$ & $\begin{array}{c}0.053 \\
(0.224)\end{array}$ & $\begin{array}{c}0.087 \\
(0.281)\end{array}$ & $\begin{array}{c}0.075 \\
(0.281)\end{array}$ \\
\hline \multicolumn{6}{|l|}{ Family controls } \\
\hline Married & $\begin{array}{c}0.508 \\
(0.499)\end{array}$ & $\begin{array}{c}0.502 \\
(0.499)\end{array}$ & $\begin{array}{c}0.514 \\
(0.499)\end{array}$ & $\begin{array}{c}0.514 \\
(0.500)\end{array}$ & $\begin{array}{c}0.502 \\
(0.500)\end{array}$ \\
\hline \multicolumn{6}{|c|}{ Dummies for number of children in home (none is omitted base category) } \\
\hline One child & $\begin{array}{c}0.159 \\
(0.366)\end{array}$ & $\begin{array}{c}0.160 \\
(0.367)\end{array}$ & $\begin{array}{c}0.158 \\
(0.365)\end{array}$ & $\begin{array}{c}0.158 \\
(0.364)\end{array}$ & $\begin{array}{c}0.162 \\
(0.368)\end{array}$ \\
\hline Two children & $\begin{array}{c}0.132 \\
(0.339)\end{array}$ & $\begin{array}{c}0.134 \\
(0.341)\end{array}$ & $\begin{array}{c}0.130 \\
(0.336)\end{array}$ & $\begin{array}{c}0.133 \\
(0.339)\end{array}$ & $\begin{array}{c}0.132 \\
(0.338)\end{array}$ \\
\hline Three children & $\begin{array}{c}0.052 \\
(0.222)\end{array}$ & $\begin{array}{c}0.051 \\
(0.221)\end{array}$ & $\begin{array}{c}0.052 \\
(0.223)\end{array}$ & $\begin{array}{c}0.050 \\
(0.217)\end{array}$ & $\begin{array}{c}0.055 \\
(0.227)\end{array}$ \\
\hline
\end{tabular}




\begin{tabular}{lccccc}
\hline & $\begin{array}{c}\text { Full } \\
\text { Sample }\end{array}$ & $\begin{array}{c}\text { Medicaid } \\
\text { Expansion } \\
\text { States }\end{array}$ & $\begin{array}{c}\text { Medicaid } \\
\text { Non- } \\
\text { Expansion } \\
\text { States }\end{array}$ & $\begin{array}{c}\text { Below } \\
\text { Median } \\
\text { Baseline } \\
\text { Uninsured } \\
\text { Rate }\end{array}$ & $\begin{array}{c}\text { Above } \\
\text { Median } \\
\text { Baseline } \\
\text { Uninsured } \\
\text { Rate }\end{array}$ \\
\hline Four children & 0.015 & 0.014 & 0.016 & 0.014 & 0.017 \\
Five children or more & $(0.123)$ & $(0.120)$ & $(0.126)$ & $(0.119)$ & $(0.127)$ \\
& 0.006 & 0.006 & 0.006 & 0.006 & 0.006 \\
& $(0.077)$ & $(0.077)$ & $(0.078)$ & $(0.077)$ & $(0.079)$
\end{tabular}

Economic controls

Education dummies (less than high school degree is omitted base category)

\begin{tabular}{|c|c|c|c|c|c|}
\hline High school degree & $\begin{array}{c}0.269 \\
(0.443)\end{array}$ & $\begin{array}{c}0.254 \\
(0.435)\end{array}$ & $\begin{array}{c}0.286 \\
(0.452)\end{array}$ & $\begin{array}{c}0.264 \\
(0.441)\end{array}$ & $\begin{array}{c}0.275 \\
(0.446)\end{array}$ \\
\hline Some College & $\begin{array}{c}0.325 \\
(0.468)\end{array}$ & $\begin{array}{c}0.323 \\
(0.467)\end{array}$ & $\begin{array}{c}0.328 \\
(0.469)\end{array}$ & $\begin{array}{c}0.321 \\
(0.467)\end{array}$ & $\begin{array}{c}0.331 \\
(0.471)\end{array}$ \\
\hline College graduate & $\begin{array}{c}0.282 \\
(0.450)\end{array}$ & $\begin{array}{c}0.301 \\
(0.458)\end{array}$ & $\begin{array}{c}0.260 \\
(0.439)\end{array}$ & $\begin{array}{c}0.319 \\
(0.466)\end{array}$ & $\begin{array}{c}0.244 \\
(0.429)\end{array}$ \\
\hline Unemployed & $\begin{array}{c}0.066 \\
(0.248)\end{array}$ & $\begin{array}{c}0.068 \\
(0.253)\end{array}$ & $\begin{array}{c}0.063 \\
(0.243)\end{array}$ & $\begin{array}{c}0.062 \\
(0.242)\end{array}$ & $\begin{array}{c}0.071 \\
(0.256)\end{array}$ \\
\hline State unemployment rate & $\begin{array}{c}7.667 \\
(1.693)\end{array}$ & $\begin{array}{c}8.071 \\
(1.735)\end{array}$ & $\begin{array}{c}7.189 \\
(1.506)\end{array}$ & $\begin{array}{c}7.350 \\
(1.594)\end{array}$ & $\begin{array}{c}8.005 \\
(1.730)\end{array}$ \\
\hline Student & $\begin{array}{c}0.122 \\
(0.327)\end{array}$ & $\begin{array}{c}0.123 \\
(0.329)\end{array}$ & $\begin{array}{c}0.120 \\
(0.325)\end{array}$ & $\begin{array}{c}0.122 \\
(0.327)\end{array}$ & $\begin{array}{c}0.123 \\
(0.328)\end{array}$ \\
\hline \multicolumn{6}{|c|}{ Income dummies (less than 10k is omitted base category) } \\
\hline Income $10 \mathrm{k}$ to $15 \mathrm{k}$ & $\begin{array}{c}0.033 \\
(0.178)\end{array}$ & $\begin{array}{c}0.030 \\
(0.172)\end{array}$ & $\begin{array}{c}0.036 \\
(0.186)\end{array}$ & $\begin{array}{c}0.029 \\
(0.168)\end{array}$ & $\begin{array}{c}0.037 \\
(0.188)\end{array}$ \\
\hline Income $15 \mathrm{k}$ to $20 \mathrm{k}$ & $\begin{array}{c}0.036 \\
(0.186)\end{array}$ & $\begin{array}{c}0.033 \\
(0.179)\end{array}$ & $\begin{array}{c}0.039 \\
(0.195)\end{array}$ & $\begin{array}{c}0.031 \\
(0.174)\end{array}$ & $\begin{array}{c}0.041 \\
(0.198)\end{array}$ \\
\hline Income $20 \mathrm{k}$ to $25 \mathrm{k}$ & $\begin{array}{c}0.041 \\
(0.198)\end{array}$ & $\begin{array}{c}0.037 \\
(0.190)\end{array}$ & $\begin{array}{c}0.044 \\
(0.206)\end{array}$ & $\begin{array}{c}0.035 \\
(0.185)\end{array}$ & $\begin{array}{c}0.046 \\
(0.210)\end{array}$ \\
\hline Income $25 \mathrm{k}$ to $35 \mathrm{k}$ & $\begin{array}{c}0.084 \\
(0.278)\end{array}$ & $\begin{array}{c}0.077 \\
(0.267)\end{array}$ & $\begin{array}{c}0.093 \\
(0.291)\end{array}$ & $\begin{array}{c}0.074 \\
(0.263)\end{array}$ & $\begin{array}{c}0.094 \\
(0.292)\end{array}$ \\
\hline Income $35 \mathrm{k}$ to $50 \mathrm{k}$ & $\begin{array}{c}0.127 \\
(0.333)\end{array}$ & $\begin{array}{c}0.118 \\
(0.323)\end{array}$ & $\begin{array}{c}0.138 \\
(0.345)\end{array}$ & $\begin{array}{c}0.118 \\
(0.323)\end{array}$ & $\begin{array}{c}0.137 \\
(0.343)\end{array}$ \\
\hline Income $50 \mathrm{k}$ to $75 \mathrm{k}$ & $\begin{array}{c}0.192 \\
(0.394)\end{array}$ & $\begin{array}{c}0.186 \\
(0.389)\end{array}$ & $\begin{array}{c}0.200 \\
(0.400)\end{array}$ & $\begin{array}{c}0.191 \\
(0.393)\end{array}$ & $\begin{array}{c}0.194 \\
(0.395)\end{array}$ \\
\hline Income more than $75 \mathrm{k}$ & $\begin{array}{c}0.433 \\
(0.495)\end{array}$ & $\begin{array}{c}0.468 \\
(0.498)\end{array}$ & $\begin{array}{c}0.391 \\
(0.488)\end{array}$ & $\begin{array}{c}0.472 \\
(0.499)\end{array}$ & $\begin{array}{c}0.394 \\
(0.488)\end{array}$ \\
\hline \multicolumn{6}{|l|}{ Exchange controls } \\
\hline State set up own exchange & $\begin{array}{c}0.344 \\
(0.475)\end{array}$ & $\begin{array}{c}0.636 \\
(0.481)\end{array}$ & $\begin{array}{c}0.298 \\
(0.497)\end{array}$ & $\begin{array}{c}0.398 \\
(0.490)\end{array}$ & $\begin{array}{c}0.274 \\
(0.446)\end{array}$ \\
\hline State exchange had glitches & $\begin{array}{c}0.084 \\
(0.277)\end{array}$ & $\begin{array}{c}0.155 \\
(0.362)\end{array}$ & $\begin{array}{c}0.073 \\
(0.259)\end{array}$ & $\begin{array}{c}0.123 \\
(0.329)\end{array}$ & $\begin{array}{c}0.033 \\
(0.178)\end{array}$ \\
\hline
\end{tabular}

Notes: Standard deviation in parentheses. 
Table 3 - Effect of ACA on Probability of Having Any Insurance Coverage

\begin{tabular}{|c|c|c|c|c|c|c|c|}
\hline & \multirow{2}{*}{$\begin{array}{l}\text { Difference-in- } \\
\text { Differences } \\
\text { All Controls }\end{array}$} & \multicolumn{6}{|c|}{ Difference-in-Difference-in-Differences } \\
\hline & & All Controls & $\begin{array}{c}\text { Demographic } \\
\text { Controls } \\
\text { Only }\end{array}$ & $\begin{array}{l}\text { Include } \\
\text { Family } \\
\text { Controls }\end{array}$ & $\begin{array}{l}\text { Include } \\
\text { Economic } \\
\text { Controls }\end{array}$ & $\begin{array}{l}\text { Include } \\
\text { Exchange } \\
\text { Controls } \\
\end{array}$ & $\begin{array}{l}\text { Use FPL- } \\
\text { Specific } \\
\text { Uninsured }\end{array}$ \\
\hline \multicolumn{8}{|c|}{ Coefficient Estimates of Interest } \\
\hline Post & $\begin{array}{c}0.027 * * * \\
(0.003)\end{array}$ & -- & -- & -- & -- & -- & -- \\
\hline $\begin{array}{l}\text { Medicaid Expansion * } \\
\text { Post }\end{array}$ & $\begin{array}{l}0.009 * \\
(0.004)\end{array}$ & $\begin{array}{l}-0.011 \\
(0.007)\end{array}$ & $\begin{array}{l}-0.004 \\
(0.007)\end{array}$ & $\begin{array}{l}-0.005 \\
(0.007)\end{array}$ & $\begin{array}{l}-0.007 \\
(0.006)\end{array}$ & $\begin{array}{l}-0.007 \\
(0.008)\end{array}$ & $\begin{array}{l}-0.006 \\
(0.008)\end{array}$ \\
\hline Uninsured Rate * Post & -- & $\begin{array}{c}0.147 * * * \\
(0.026)\end{array}$ & $\begin{array}{c}0.163 * * * \\
(0.030)\end{array}$ & $\begin{array}{c}0.165^{* * *} \\
(0.029)\end{array}$ & $\begin{array}{c}0.145^{* * *} \\
(0.027)\end{array}$ & $\begin{array}{c}0.163 * * * \\
(0.030)\end{array}$ & $\begin{array}{c}0.192 * * * \\
(0.025)\end{array}$ \\
\hline $\begin{array}{l}\text { Uninsured Rate } * \text { Medi- } \\
\text { caid Expansion } * \text { Post }\end{array}$ & -- & $\begin{array}{c}0.144 * * * \\
(0.034)\end{array}$ & $\begin{array}{c}0.140 * * * \\
(0.036)\end{array}$ & $\begin{array}{l}0.141 * * * \\
(0.035)\end{array}$ & $\begin{array}{c}0.148 * * * \\
(0.033)\end{array}$ & $\begin{array}{l}0.132 * * * \\
(0.038)\end{array}$ & $\begin{array}{c}0.061 * * \\
(0.022)\end{array}$ \\
\hline \multicolumn{8}{|c|}{ Implied Effects of ACA at Mean Pre-Treatment Uninsured Rates } \\
\hline $\begin{array}{l}\text { ACA without Medicaid } \\
\text { Expansion }\end{array}$ & $\begin{array}{c}0.027 * * * \\
(0.003)\end{array}$ & $\begin{array}{c}0.030 * * * \\
(0.005)\end{array}$ & $\begin{array}{c}0.033 * * * \\
(0.006)\end{array}$ & $\begin{array}{c}0.034 * * * \\
(0.006)\end{array}$ & $\begin{array}{c}0.029 * * * \\
(0.005)\end{array}$ & $\begin{array}{c}0.033 * * * \\
(0.006)\end{array}$ & $\begin{array}{c}0.033 * * * \\
(0.004)\end{array}$ \\
\hline Medicaid Expansion & $\begin{array}{l}0.009 * \\
(0.004)\end{array}$ & $\begin{array}{c}0.029 * * * \\
(0.007)\end{array}$ & $\begin{array}{c}0.028 * * * \\
(0.007)\end{array}$ & $\begin{array}{c}0.029 * * * \\
(0.007)\end{array}$ & $\begin{array}{c}0.030 * * * \\
(0.007)\end{array}$ & $\begin{array}{c}0.027 * * * \\
(0.008)\end{array}$ & $\begin{array}{c}0.023 * * \\
(0.009)\end{array}$ \\
\hline $\begin{array}{l}\text { Full ACA (with } \\
\text { Medicaid Expansion) }\end{array}$ & $\begin{array}{c}0.036 * * * \\
(0.003)\end{array}$ & $\begin{array}{c}0.059 * * * \\
(0.004)\end{array}$ & $\begin{array}{c}0.062 * * * \\
(0.004)\end{array}$ & $\begin{array}{c}0.062 * * * \\
(0.004)\end{array}$ & $\begin{array}{c}0.060 * * * \\
(0.004)\end{array}$ & $\begin{array}{c}0.060 * * * \\
(0.005)\end{array}$ & $\begin{array}{c}0.057 * * * \\
(0.007)\end{array}$ \\
\hline Area Fixed Effects & YES & YES & YES & YES & YES & YES & YES \\
\hline Time Fixed Effects & NO & YES & YES & YES & YES & YES & YES \\
\hline Demographic Controls & YES & YES & YES & YES & YES & YES & YES \\
\hline Family Controls & NO & YES & $\mathrm{NO}$ & YES & $\mathrm{NO}$ & $\mathrm{NO}$ & YES \\
\hline Economic Controls & NO & YES & NO & NO & YES & $\mathrm{NO}$ & YES \\
\hline Exchange Controls & NO & YES & NO & NO & NO & YES & YES \\
\hline
\end{tabular}


Table 4 - Effect of ACA on Sources of Insurance Coverage

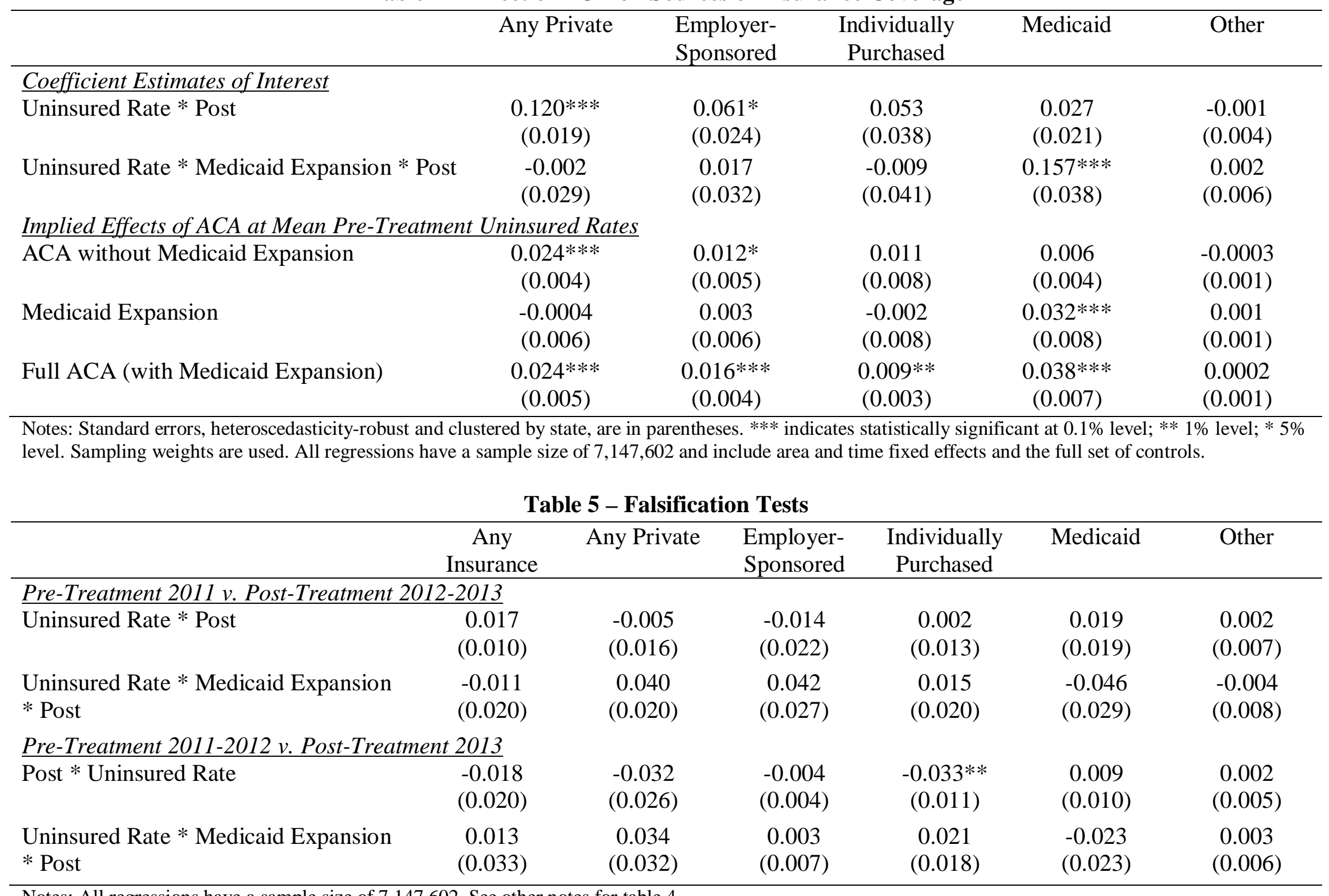

Notes: All regressions have a sample size of 7,147,602. See other notes for table 4 . 
Table 6 - Event Study Results

\begin{tabular}{|c|c|c|c|c|c|c|}
\hline & $\begin{array}{c}\text { Any } \\
\text { Insurance }\end{array}$ & $\begin{array}{c}\text { Any } \\
\text { Private }\end{array}$ & $\begin{array}{l}\text { Employer- } \\
\text { Sponsored }\end{array}$ & $\begin{array}{c}\text { Individu- } \\
\text { ally } \\
\text { Purchased }\end{array}$ & Medicaid & Other \\
\hline \multicolumn{7}{|l|}{ Coefficient Estimates of Interest (2013 is Base Year) } \\
\hline Uninsured Rate * Year 2011 & $\begin{array}{l}0.0002 \\
(0.015)\end{array}$ & $\begin{array}{c}0.030 \\
(0.029)\end{array}$ & $\begin{array}{c}0.024 \\
(0.031)\end{array}$ & $\begin{array}{c}0.025 \\
(0.016)\end{array}$ & $\begin{array}{l}-0.022 \\
(0.021)\end{array}$ & $\begin{array}{l}-0.003 \\
(0.008)\end{array}$ \\
\hline Uninsured Rate * Year 2012 & $\begin{array}{c}0.032 \\
(0.025)\end{array}$ & $\begin{array}{c}0.038 \\
(0.026)\end{array}$ & $\begin{array}{c}0.021 \\
(0.022)\end{array}$ & $\begin{array}{c}0.042 * * * \\
(0.011)\end{array}$ & $\begin{array}{c}-0.001 \\
(0.006)\end{array}$ & $\begin{array}{r}-0.0005 \\
(0.003)\end{array}$ \\
\hline Uninsured Rate * Year 2014 & $\begin{array}{c}0.158 * * * \\
(0.037)\end{array}$ & $\begin{array}{c}0.143 * * * \\
(0.032)\end{array}$ & $\begin{array}{c}0.076^{* * *} * \\
(0.012)\end{array}$ & $\begin{array}{c}0.074 \\
(0.042)\end{array}$ & $\begin{array}{c}0.020 \\
(0.015)\end{array}$ & $\begin{array}{l}-0.002 \\
(0.003)\end{array}$ \\
\hline Uninsured Rate * Medicaid Expansion * Year 2011 & $\begin{array}{c}-0.00002 \\
(0.033)\end{array}$ & $\begin{array}{l}-0.045 \\
(0.034)\end{array}$ & $\begin{array}{c}-0.054 \\
(0.038)\end{array}$ & $\begin{array}{c}-0.022 \\
(0.020)\end{array}$ & $\begin{array}{c}0.044 \\
(0.035)\end{array}$ & $\begin{array}{c}0.001 \\
(0.009)\end{array}$ \\
\hline Uninsured Rate * Medicaid Expansion * Year 2012 & $\begin{array}{l}-0.027 \\
(0.026)\end{array}$ & $\begin{array}{c}-0.018 \\
(0.036)\end{array}$ & $\begin{array}{l}-0.030 \\
(0.031)\end{array}$ & $\begin{array}{c}-0.019 \\
(0.025)\end{array}$ & $\begin{array}{l}-0.001 \\
(0.017)\end{array}$ & $\begin{array}{l}-0.007 \\
(0.006)\end{array}$ \\
\hline Uninsured Rate * Medicaid Expansion * Year 2014 & $\begin{array}{c}0.135 * * \\
(0.045)\end{array}$ & $\begin{array}{c}-0.023 \\
(0.040)\end{array}$ & $\begin{array}{l}-0.010 \\
(0.022)\end{array}$ & $\begin{array}{c}-0.023 \\
(0.045)\end{array}$ & $\begin{array}{c}0.171 * * * \\
(0.036)\end{array}$ & $\begin{array}{c}0.001 \\
(0.006)\end{array}$ \\
\hline \multicolumn{7}{|c|}{ Implied Effects of ACA at Mean Pre-Treatment Uninsured Rates } \\
\hline ACA without Medicaid Expansion & $\begin{array}{c}0.032 * * * \\
(0.008)\end{array}$ & $\begin{array}{c}0.029 * * * \\
(0.006)\end{array}$ & $\begin{array}{c}0.016 * * * \\
(0.003)\end{array}$ & $\begin{array}{c}0.015 \\
(0.009)\end{array}$ & $\begin{array}{c}0.004 \\
(0.003)\end{array}$ & $\begin{array}{c}-0.001 \\
(0.001)\end{array}$ \\
\hline Medicaid Expansion & $\begin{array}{c}0.027 * * \\
(0.009)\end{array}$ & $\begin{array}{c}-0.005 \\
(0.008)\end{array}$ & $\begin{array}{l}-0.002 \\
(0.005)\end{array}$ & $\begin{array}{c}-0.005 \\
(0.009)\end{array}$ & $\begin{array}{c}0.035 * * * \\
(0.007)\end{array}$ & $\begin{array}{l}0.0001 \\
(0.001)\end{array}$ \\
\hline Full ACA (with Medicaid Expansion) & $\begin{array}{c}0.060 * * * \\
(0.005)\end{array}$ & $\begin{array}{c}0.024 * * * \\
(0.005)\end{array}$ & $\begin{array}{c}0.013 * * * \\
(0.004)\end{array}$ & $\begin{array}{c}0.011 * * * \\
(0.003)\end{array}$ & $\begin{array}{c}0.039 * * * \\
(0.007)\end{array}$ & $\begin{array}{c}-0.0004 \\
(0.001)\end{array}$ \\
\hline
\end{tabular}


Table 7 - Income Subsamples

\begin{tabular}{|c|c|c|c|c|c|c|}
\hline & $\begin{array}{c}\text { Any } \\
\text { Insurance }\end{array}$ & $\begin{array}{c}\text { Any } \\
\text { Private }\end{array}$ & $\begin{array}{l}\text { Employer- } \\
\text { Provided }\end{array}$ & $\begin{array}{c}\text { Individ- } \\
\text { ually } \\
\text { Purchased }\end{array}$ & Medicaid & Other \\
\hline \multicolumn{7}{|c|}{ Under 138\% FPL (Pre-Treatment Uninsured Rate $=0.390)$} \\
\hline $\begin{array}{l}\text { ACA w/o } \\
\text { Medicaid }\end{array}$ & $\begin{array}{c}0.048 * * * \\
(0.016)\end{array}$ & $\begin{array}{l}0.032 * * \\
(0.011)\end{array}$ & $\begin{array}{c}0.022 * * \\
(0.007)\end{array}$ & $\begin{array}{c}0.013 \\
(0.014)\end{array}$ & $\begin{array}{c}0.009 \\
(0.011)\end{array}$ & $\begin{array}{l}0.005 \\
(0.004)\end{array}$ \\
\hline $\begin{array}{l}\text { Medicaid } \\
\text { Expansion }\end{array}$ & $\begin{array}{l}0.055^{*} \\
(0.026)\end{array}$ & $\begin{array}{l}-0.018 \\
(0.015)\end{array}$ & $\begin{array}{l}-0.010 \\
(0.010)\end{array}$ & $\begin{array}{l}-0.010 \\
(0.015)\end{array}$ & $\begin{array}{c}0.080 * * * \\
(0.022)\end{array}$ & $\begin{array}{c}-0.002 \\
(0.005)\end{array}$ \\
\hline $\begin{array}{l}\text { Full ACA (w/ } \\
\text { Medicaid) }\end{array}$ & $\begin{array}{c}0.103 * * * \\
(0.021)\end{array}$ & $\begin{array}{c}0.014 \\
(0.010)\end{array}$ & $\begin{array}{c}0.012 \\
(0.007)\end{array}$ & $\begin{array}{c}0.003 \\
(0.006)\end{array}$ & $\begin{array}{l}0.088^{* * * *} \\
(0.019)\end{array}$ & $\begin{array}{c}0.002 \\
(0.003)\end{array}$ \\
\hline Sample Size & $1,382,395$ & $1,382,395$ & $1,382,395$ & $1,382,395$ & $1,382,395$ & $1,382,395$ \\
\hline \multicolumn{7}{|c|}{$138 \%-400 \%$ FPL (Pre-Treatment Uninsured Rate $=0.237)$} \\
\hline $\begin{array}{l}\text { ACA w/o } \\
\text { Medicaid }\end{array}$ & $\begin{array}{c}0.046^{* * * *} \\
(0.007)\end{array}$ & $\begin{array}{c}0.041^{* * * *} \\
(0.006)\end{array}$ & $\begin{array}{c}0.022 * * * \\
(0.005)\end{array}$ & $\begin{array}{l}0.018^{*} \\
(0.008)\end{array}$ & $\begin{array}{c}0.006 \\
(0.005)\end{array}$ & $\begin{array}{l}0.0002 \\
(0.001)\end{array}$ \\
\hline $\begin{array}{l}\text { Medicaid } \\
\text { Expansion }\end{array}$ & $\begin{array}{c}0.016 \\
(0.011)\end{array}$ & $\begin{array}{c}0.009 \\
(0.010)\end{array}$ & $\begin{array}{c}0.014 \\
(0.009)\end{array}$ & $\begin{array}{c}-0.0004 \\
(0.010)\end{array}$ & $\begin{array}{c}0.010 \\
(0.008)\end{array}$ & $\begin{array}{c}-0.0003 \\
(0.002)\end{array}$ \\
\hline $\begin{array}{l}\text { Full ACA (w/ } \\
\text { Medicaid) }\end{array}$ & $\begin{array}{c}0.063 * * * \\
(0.008)\end{array}$ & $\begin{array}{c}0.050^{* * * *} \\
(0.008)\end{array}$ & $\begin{array}{c}0.036^{* * * *} \\
(0.007)\end{array}$ & $\begin{array}{c}0.017 * * * \\
(0.005)\end{array}$ & $\begin{array}{l}0.015^{*} \\
(0.006)\end{array}$ & $\begin{array}{c}-0.0001 \\
(0.002)\end{array}$ \\
\hline Sample Size & $2,827,034$ & $2,827,034$ & $2,827,034$ & $2,827,034$ & $2,827,034$ & $2,827,034$ \\
\hline \multicolumn{7}{|c|}{ Over $400 \%$ FPL (Pre-Treatment Uninsured Rate $=0.067)$} \\
\hline $\begin{array}{l}\text { ACA w/o } \\
\text { Medicaid }\end{array}$ & $\begin{array}{c}0.013 * * * * \\
(0.001)\end{array}$ & $\begin{array}{c}0.013 * * * \\
(0.002)\end{array}$ & $\begin{array}{c}0.007 \\
(0.006)\end{array}$ & $\begin{array}{c}0.004 \\
(0.005)\end{array}$ & $\begin{array}{l}-0.001 \\
(0.001)\end{array}$ & $\begin{array}{l}0.0002 \\
(0.001)\end{array}$ \\
\hline $\begin{array}{l}\text { Medicaid } \\
\text { Expansion }\end{array}$ & $\begin{array}{c}0.004 \\
(0.003)\end{array}$ & $\begin{array}{c}-0.002 \\
(0.003)\end{array}$ & $\begin{array}{l}-0.004 \\
(0.008)\end{array}$ & $\begin{array}{l}0.0002 \\
(0.006)\end{array}$ & $\begin{array}{c}0.006^{* *} \\
(0.002)\end{array}$ & $\begin{array}{l}0.0002 \\
(0.002)\end{array}$ \\
\hline $\begin{array}{l}\text { Full ACA (w/ } \\
\text { Medicaid) }\end{array}$ & $\begin{array}{c}0.016 * * * \\
(0.002)\end{array}$ & $\begin{array}{c}0.011^{* * * *} \\
(0.002)\end{array}$ & $\begin{array}{c}0.003 \\
(0.004)\end{array}$ & $\begin{array}{c}0.004 \\
(0.003)\end{array}$ & $\begin{array}{l}0.006^{* *} \\
(0.002)\end{array}$ & $\begin{array}{l}0.0004 \\
(0.001)\end{array}$ \\
\hline Sample Size & $2,946,751$ & $2,946,751$ & $2,946,751$ & $2,946,751$ & $2,946,751$ & $2,946,751$ \\
\hline
\end{tabular}

Notes: Standard errors, heteroscedasticity-robust and clustered by state, are in parentheses. $* * *$ indicates statistically significant at $0.1 \%$ level; ** $1 \%$ level; * 5\% level. Sampling weights are used. All regressions include area and time fixed effects and the full set of controls. 
Table 8 - Age Subsamples

\begin{tabular}{|c|c|c|c|c|c|c|}
\hline & $\begin{array}{c}\text { Any } \\
\text { Insurance }\end{array}$ & $\begin{array}{c}\text { Any } \\
\text { Private }\end{array}$ & $\begin{array}{l}\text { Employer- } \\
\text { Provided }\end{array}$ & $\begin{array}{c}\text { Individ- } \\
\text { ually } \\
\text { Purchased }\end{array}$ & Medicaid & Other \\
\hline \multicolumn{7}{|c|}{ Ages 18-34 (Pre-Treatment Uninsured Rate $=0.257)$} \\
\hline $\begin{array}{l}\text { ACA w/o } \\
\text { Medicaid }\end{array}$ & $\begin{array}{c}0.036^{* * * *} \\
(0.006)\end{array}$ & $\begin{array}{c}0.024^{* * *} \\
(0.005)\end{array}$ & $\begin{array}{c}0.016 * * * \\
(0.004)\end{array}$ & $\begin{array}{c}0.006 \\
(0.007)\end{array}$ & $\begin{array}{l}0.010^{*} \\
(0.005)\end{array}$ & $\begin{array}{c}0.002 \\
(0.002)\end{array}$ \\
\hline $\begin{array}{l}\text { Medicaid } \\
\text { Expansion }\end{array}$ & $\begin{array}{c}0.037 * * * \\
(0.009)\end{array}$ & $\begin{array}{l}-0.003 \\
(0.008)\end{array}$ & $\begin{array}{l}-0.005 \\
(0.007)\end{array}$ & $\begin{array}{c}0.005 \\
(0.008)\end{array}$ & $\begin{array}{c}0.044 * * * \\
(0.010)\end{array}$ & $\begin{array}{c}0.001 \\
(0.002)\end{array}$ \\
\hline $\begin{array}{l}\text { Full ACA (w/ } \\
\text { Medicaid) }\end{array}$ & $\begin{array}{c}0.073^{* * * *} \\
(0.006)\end{array}$ & $\begin{array}{c}0.021 * * \\
(0.007)\end{array}$ & $\begin{array}{c}0.011 \\
(0.006)\end{array}$ & $\begin{array}{l}0.011^{*} \\
(0.004)\end{array}$ & $\begin{array}{c}0.054 * * * \\
(0.009)\end{array}$ & $\begin{array}{c}0.003 \\
(0.001)\end{array}$ \\
\hline Sample Size & $2,274,699$ & $2,274,699$ & $2,274,699$ & $2,274,699$ & $2,274,699$ & $2,274,699$ \\
\hline \multicolumn{7}{|c|}{ Ages 35-49 (Pre-Treatment Uninsured Rate $=0.201)$} \\
\hline $\begin{array}{l}\text { ACA w/o } \\
\text { Medicaid }\end{array}$ & $\begin{array}{c}0.028 * * * \\
(0.006)\end{array}$ & $\begin{array}{c}0.026 * * * \\
(0.004)\end{array}$ & $\begin{array}{c}0.014 * * \\
(0.005)\end{array}$ & $\begin{array}{c}0.010 \\
(0.006)\end{array}$ & $\begin{array}{c}0.004 \\
(0.005)\end{array}$ & $\begin{array}{c}-0.002 * * \\
(0.001)\end{array}$ \\
\hline $\begin{array}{l}\text { Medicaid } \\
\text { Expansion }\end{array}$ & $\begin{array}{c}0.021^{* * *} \\
(0.007)\end{array}$ & $\begin{array}{l}-0.005 \\
(0.006)\end{array}$ & $\begin{array}{c}0.001 \\
(0.006)\end{array}$ & $\begin{array}{l}-0.004 \\
(0.007)\end{array}$ & $\begin{array}{c}0.024 * * \\
(0.009)\end{array}$ & $\begin{array}{l}0.004 * \\
(0.001)\end{array}$ \\
\hline $\begin{array}{l}\text { Full ACA (w/ } \\
\text { Medicaid) }\end{array}$ & $\begin{array}{c}0.049 * * * \\
(0.005)\end{array}$ & $\begin{array}{c}0.021^{* * * *} \\
(0.004)\end{array}$ & $\begin{array}{c}0.016 * * * \\
(0.004)\end{array}$ & $\begin{array}{l}0.006^{*} \\
(0.003)\end{array}$ & $\begin{array}{c}0.028 * * * \\
(0.007)\end{array}$ & $\begin{array}{c}0.001 \\
(0.001)\end{array}$ \\
\hline Sample Size & $2,238,724$ & $2,238,724$ & $2,238,724$ & $2,238,724$ & $2,238,724$ & $2,238,724$ \\
\hline \multicolumn{7}{|c|}{ Ages 50-64 (Pre-Treatment Uninsured Rate $=0.145)$} \\
\hline $\begin{array}{l}\text { ACA w/o } \\
\text { Medicaid }\end{array}$ & $\begin{array}{c}0.025^{* * *} \\
(0.003)\end{array}$ & $\begin{array}{c}0.022 * * * \\
(0.003)\end{array}$ & $\begin{array}{c}0.006 \\
(0.007)\end{array}$ & $\begin{array}{c}0.014 \\
(0.009)\end{array}$ & $\begin{array}{c}0.003 \\
(0.003)\end{array}$ & $\begin{array}{l}0.0001 \\
(0.001)\end{array}$ \\
\hline $\begin{array}{l}\text { Medicaid } \\
\text { Expansion }\end{array}$ & $\begin{array}{c}0.029 * * * \\
(0.005)\end{array}$ & $\begin{array}{c}0.007 \\
(0.005)\end{array}$ & $\begin{array}{c}0.011 \\
(0.008)\end{array}$ & $\begin{array}{l}-0.001 \\
(0.009)\end{array}$ & $\begin{array}{c}0.025 * * * \\
(0.005)\end{array}$ & $\begin{array}{l}-0.002 \\
(0.002)\end{array}$ \\
\hline $\begin{array}{l}\text { Full ACA (w/ } \\
\text { Medicaid) }\end{array}$ & $\begin{array}{c}0.053 * * * \\
(0.004)\end{array}$ & $\begin{array}{c}0.029 * * * \\
(0.005)\end{array}$ & $\begin{array}{c}0.017 * * * \\
(0.004)\end{array}$ & $\begin{array}{c}0.013 * * * \\
(0.003)\end{array}$ & $\begin{array}{c}0.028 * * * \\
(0.004)\end{array}$ & $\begin{array}{l}-0.002 \\
(0.002)\end{array}$ \\
\hline Sample Size & $2,634,179$ & $2,634,179$ & $2,634,179$ & $2,634,179$ & $2,634,179$ & $2,634,179$ \\
\hline
\end{tabular}

Notes: See notes for table 7. 
Table 9 - Race/Ethnicity Subsamples

\begin{tabular}{|c|c|c|c|c|c|c|}
\hline & $\begin{array}{c}\text { Any } \\
\text { Insurance }\end{array}$ & $\begin{array}{c}\text { Any } \\
\text { Private }\end{array}$ & $\begin{array}{c}\text { Employer- } \\
\text { Provided }\end{array}$ & $\begin{array}{c}\text { Individ- } \\
\text { ually } \\
\text { Purchased }\end{array}$ & Medicaid & Other \\
\hline \multicolumn{7}{|c|}{ Non-Hispanic White (Pre-Treatment Uninsured Rate $=0.144)$} \\
\hline $\begin{array}{l}\text { ACA w/o } \\
\text { Medicaid }\end{array}$ & $\begin{array}{c}0.016^{* * * *} \\
(0.003)\end{array}$ & $\begin{array}{c}0.009 * * \\
(0.003)\end{array}$ & $\begin{array}{c}0.003 \\
(0.006)\end{array}$ & $\begin{array}{c}0.002 \\
(0.005)\end{array}$ & $\begin{array}{c}0.010 * * * \\
(0.002)\end{array}$ & $\begin{array}{l}-0.002 \\
(0.001)\end{array}$ \\
\hline $\begin{array}{l}\text { Medicaid } \\
\text { Expansion }\end{array}$ & $\begin{array}{c}0.041 * * * \\
(0.005)\end{array}$ & $\begin{array}{c}0.007 \\
(0.006)\end{array}$ & $\begin{array}{c}0.007 \\
(0.008)\end{array}$ & $\begin{array}{c}0.003 \\
(0.006)\end{array}$ & $\begin{array}{c}0.038^{* * * *} \\
(0.008)\end{array}$ & $\begin{array}{l}-0.001 \\
(0.002)\end{array}$ \\
\hline $\begin{array}{l}\text { Full ACA (w/ } \\
\text { Medicaid) }\end{array}$ & $\begin{array}{c}0.057 * * * \\
(0.005)\end{array}$ & $\begin{array}{c}0.016^{* * *} \\
(0.005)\end{array}$ & $\begin{array}{l}0.009^{*} \\
(0.004)\end{array}$ & $\begin{array}{c}0.005 \\
(0.003)\end{array}$ & $\begin{array}{c}0.049 * * * \\
(0.007)\end{array}$ & $\begin{array}{l}-0.003 \\
(0.001)\end{array}$ \\
\hline Sample Size & $4,856,738$ & $4,856,738$ & $4,856,738$ & $4,856,738$ & $4,856,738$ & $4,856,738$ \\
\hline \multicolumn{7}{|c|}{ Non-White $($ Pre-Treatment Uninsured Rate $=0.303)$} \\
\hline $\begin{array}{l}\text { ACA w/o } \\
\text { Medicaid }\end{array}$ & $\begin{array}{c}0.037 * * \\
(0.012)\end{array}$ & $\begin{array}{c}0.036 * * * \\
(0.010)\end{array}$ & $\begin{array}{c}0.020 * * * \\
(0.004)\end{array}$ & $\begin{array}{c}0.018 \\
(0.011)\end{array}$ & $\begin{array}{l}-0.001 \\
(0.005)\end{array}$ & $\begin{array}{l}0.0001 \\
(0.002)\end{array}$ \\
\hline $\begin{array}{l}\text { Medicaid } \\
\text { Expansion }\end{array}$ & $\begin{array}{c}0.042^{* * *} \\
(0.013)\end{array}$ & $\begin{array}{l}-0.002 \\
(0.013)\end{array}$ & $\begin{array}{c}0.002 \\
(0.009)\end{array}$ & $\begin{array}{l}-0.001 \\
(0.012)\end{array}$ & $\begin{array}{c}0.044 * * * \\
(0.012)\end{array}$ & $\begin{array}{c}0.004 \\
(0.003)\end{array}$ \\
\hline $\begin{array}{l}\text { Full ACA (w/ } \\
\text { Medicaid) }\end{array}$ & $\begin{array}{c}0.079 * * * \\
(0.007)\end{array}$ & $\begin{array}{c}0.034 * * * \\
(0.008)\end{array}$ & $\begin{array}{c}0.022 * * \\
(0.007)\end{array}$ & $\begin{array}{c}0.017 * * \\
(0.005)\end{array}$ & $\begin{array}{c}0.043^{* * * *} \\
(0.010)\end{array}$ & $\begin{array}{l}0.004 * \\
(0.002)\end{array}$ \\
\hline Sample Size & $2,290,864$ & $2,290,864$ & $2,290,864$ & $2,290,864$ & $2,290,864$ & $2,290,864$ \\
\hline
\end{tabular}

Notes: See notes for table 7.

Table 10 - Marital Status Subsamples

\begin{tabular}{lcccccc}
\hline & $\begin{array}{c}\text { Any } \\
\text { Insurance }\end{array}$ & $\begin{array}{c}\text { Any } \\
\text { Private }\end{array}$ & $\begin{array}{c}\text { Employer- } \\
\text { Provided }\end{array}$ & $\begin{array}{c}\text { Individ- } \\
\text { ually } \\
\text { Purchased }\end{array}$ & Medicaid & Other \\
\hline \multicolumn{7}{c}{ Married (Pre-Treatment Uninsured Rate $=0.141)$} \\
ACA w/o & $0.021^{* * *}$ & $0.020^{* * *}$ & $0.008^{* *}$ & $0.012 *$ & 0.003 & -0.001 \\
Medicaid & $(0.005)$ & $(0.003)$ & $(0.002)$ & $(0.005)$ & $(0.003)$ & $(0.001)$ \\
Medicaid & $0.020^{* * *}$ & -0.0003 & 0.003 & -0.002 & $0.021^{* * *}$ & 0.0005 \\
Expansion & $(0.005)$ & $(0.004)$ & $(0.004)$ & $(0.005)$ & $(0.004)$ & $(0.001)$ \\
Full ACA (w/ & $0.041^{* * *}$ & $0.019 * * *$ & $0.011^{* * *}$ & $0.009 * * *$ & $0.024 * * *$ & -0.0002 \\
Medicaid) & $(0.003)$ & $(0.003)$ & $(0.003)$ & $(0.002)$ & $(0.003)$ & $(0.001)$ \\
Sample Size & $3,993,448$ & $3,993,448$ & $3,993,448$ & $3,993,448$ & $3,993,448$ & $3,993,448$ \\
Unmarried (Pre-Treatment Uninsured Rate $=0.267)$ & & & \\
ACA w/o & $0.038^{* * *}$ & $0.026 * * *$ & $0.019 *$ & 0.006 & 0.009 & 0.0004 \\
Medicaid & $(0.007)$ & $(0.006)$ & $(0.008)$ & $(0.010)$ & $(0.006)$ & $(0.002)$ \\
Medicaid & $0.045^{* * *}$ & 0.004 & 0.003 & 0.004 & $0.046 * * *$ & 0.001 \\
Expansion & $(0.010)$ & $(0.010)$ & $(0.010)$ & $(0.011)$ & $(0.013)$ & $(0.003)$ \\
Full ACA (w/ & $0.083^{* * *}$ & $0.030^{* * *}$ & $0.022^{* *}$ & $0.010^{*}$ & $0.055^{* * *}$ & 0.002 \\
Medicaid) & $(0.007)$ & $(0.008)$ & $(0.007)$ & $(0.004)$ & $(0.011)$ & $(0.001)$ \\
Sample Size & $3,154,154$ & $3,154,154$ & $3,154,154$ & $3,154,154$ & $3,154,154$ & $3,154,154$ \\
\hline
\end{tabular}

Notes: See notes for table 7. 


\begin{tabular}{|c|c|c|c|c|c|c|c|}
\hline & \multirow{2}{*}{$\begin{array}{l}\text { Difference-in- } \\
\text { Differences } \\
\text { All Controls }\end{array}$} & \multicolumn{6}{|c|}{ Difference-in-Difference-in-Differences } \\
\hline & & All Controls & $\begin{array}{c}\text { Demographic } \\
\text { Controls } \\
\text { Only }\end{array}$ & $\begin{array}{l}\text { Include } \\
\text { Family } \\
\text { Controls }\end{array}$ & $\begin{array}{l}\text { Include } \\
\text { Economic } \\
\text { Controls }\end{array}$ & $\begin{array}{l}\text { Include } \\
\text { Exchange } \\
\text { Controls }\end{array}$ & $\begin{array}{l}\text { Use FPL- } \\
\text { Specific } \\
\text { Uninsured }\end{array}$ \\
\hline \multicolumn{8}{|c|}{ Coefficient Estimates of Interest } \\
\hline Post & $\begin{array}{c}0.005 \\
(0.003)\end{array}$ & -- & -- & -- & -- & -- & -- \\
\hline $\begin{array}{l}\text { Medicaid Expansion * } \\
\text { Post }\end{array}$ & $\begin{array}{l}-0.000 \\
(0.003)\end{array}$ & $\begin{array}{l}-0.007 \\
(0.005)\end{array}$ & $\begin{array}{c}0.001 \\
(0.005)\end{array}$ & $\begin{array}{c}0.001 \\
(0.005)\end{array}$ & $\begin{array}{l}-0.005 \\
(0.005)\end{array}$ & $\begin{array}{c}0.003 \\
(0.006)\end{array}$ & $\begin{array}{l}-0.003 \\
(0.006)\end{array}$ \\
\hline Uninsured Rate * Post & -- & $\begin{array}{l}0.062^{*} \\
(0.025)\end{array}$ & $\begin{array}{c}0.086^{* * * *} \\
(0.023)\end{array}$ & $\begin{array}{c}0.088 * * * \\
(0.024)\end{array}$ & $\begin{array}{l}0.059 * \\
(0.023)\end{array}$ & $\begin{array}{c}0.086^{* * * *} \\
(0.023)\end{array}$ & $\begin{array}{l}0.061^{*} \\
(0.024)\end{array}$ \\
\hline $\begin{array}{l}\text { Uninsured Rate * Post * } \\
\text { Medicaid Expansion }\end{array}$ & -- & $\begin{array}{c}0.019 \\
(0.015)\end{array}$ & $\begin{array}{l}-0.004 \\
(0.026)\end{array}$ & $\begin{array}{l}-0.002 \\
(0.027)\end{array}$ & $\begin{array}{c}0.022 \\
(0.029)\end{array}$ & $\begin{array}{l}-0.009 \\
(0.030)\end{array}$ & $\begin{array}{c}0.017 \\
(0.032)\end{array}$ \\
\hline \multicolumn{8}{|c|}{ Implied Effects of ACA at Mean Pre-Treatment Uninsured Rates } \\
\hline $\begin{array}{l}\text { ACA without Medicaid } \\
\text { Expansion }\end{array}$ & $\begin{array}{c}0.005 \\
(0.003)\end{array}$ & $\begin{array}{l}0.011 * \\
(0.004)\end{array}$ & $\begin{array}{l}0.017 * * * \\
(0.008)\end{array}$ & $\begin{array}{l}0.018 * * * \\
(0.005)\end{array}$ & $\begin{array}{l}0.012 * \\
(0.005)\end{array}$ & $\begin{array}{l}0.017 * * \\
(0.0085\end{array}$ & $\begin{array}{l}0.013 * \\
(0.005)\end{array}$ \\
\hline Medicaid Expansion & $\begin{array}{l}-0.002 \\
(0.003)\end{array}$ & $\begin{array}{c}0.007 \\
(0.006)\end{array}$ & $\begin{array}{l}-0.001 \\
(0.009)\end{array}$ & $\begin{array}{l}-0.001 \\
(0.005)\end{array}$ & $\begin{array}{c}0.004 \\
(0.006)\end{array}$ & $\begin{array}{l}-0.002 \\
(0.006)\end{array}$ & $\begin{array}{c}0.004 \\
(0.006)\end{array}$ \\
\hline $\begin{array}{l}\text { Full ACA (with } \\
\text { Medicaid Expansion) }\end{array}$ & $\begin{array}{c}0.003 \\
(0.002)\end{array}$ & $\begin{array}{l}0.018 * * * \\
(0.004)\end{array}$ & $\begin{array}{l}0.017 * * * \\
(0.003)\end{array}$ & $\begin{array}{c}0.017 * * * \\
(0.003)\end{array}$ & $\begin{array}{c}0.017 * * * \\
(0.003)\end{array}$ & $\begin{array}{c}0.016 * * * \\
(0.004)\end{array}$ & $\begin{array}{c}0.016 * * * \\
(0.005)\end{array}$ \\
\hline Area Fixed Effects & YES & YES & YES & YES & YES & YES & YES \\
\hline Time Fixed Effects & NO & YES & YES & YES & YES & YES & YES \\
\hline Demographic Controls & YES & YES & YES & YES & YES & YES & YES \\
\hline Family Controls & $\mathrm{NO}$ & YES & NO & YES & $\mathrm{NO}$ & $\mathrm{NO}$ & YES \\
\hline Economic Controls & NO & YES & NO & $\mathrm{NO}$ & YES & NO & YES \\
\hline Exchange Controls & NO & YES & NO & NO & NO & YES & YES \\
\hline
\end{tabular}


Appendix Table A2 (online publication only) - Additional Specifications for Individually Purchased Insurance

\begin{tabular}{|c|c|c|c|c|c|c|c|}
\hline & \multirow{2}{*}{$\begin{array}{l}\text { Difference-in- } \\
\text { Differences } \\
\text { All Controls }\end{array}$} & \multicolumn{6}{|c|}{ Difference-in-Difference-in-Differences } \\
\hline & & All Controls & $\begin{array}{c}\text { Demographic } \\
\text { Controls } \\
\text { Only }\end{array}$ & $\begin{array}{l}\text { Include } \\
\text { Family } \\
\text { Controls }\end{array}$ & $\begin{array}{c}\text { Include } \\
\text { Economic } \\
\text { Controls } \\
\end{array}$ & $\begin{array}{l}\text { Include } \\
\text { Exchange } \\
\text { Controls } \\
\end{array}$ & $\begin{array}{l}\text { Use FPL- } \\
\text { Specific } \\
\text { Uninsured }\end{array}$ \\
\hline \multicolumn{8}{|c|}{ Coefficient Estimates of Interest } \\
\hline Post & $\begin{array}{c}0.019 * * * \\
(0.002)\end{array}$ & -- & -- & -- & -- & -- & -- \\
\hline $\begin{array}{l}\text { Medicaid Expansion * } \\
\text { Post }\end{array}$ & $\begin{array}{l}-0.010 * * * \\
(0.003)\end{array}$ & $\begin{array}{l}-0.006 \\
(0.007)\end{array}$ & $\begin{array}{l}-0.008 \\
(0.008)\end{array}$ & $\begin{array}{l}-0.008 \\
(0.008)\end{array}$ & $\begin{array}{l}-0.007 \\
(0.008)\end{array}$ & $\begin{array}{l}-0.007 \\
(0.008)\end{array}$ & $\begin{array}{l}-0.006 \\
(0.008)\end{array}$ \\
\hline Uninsured Rate * Post & -- & $\begin{array}{c}0.063 \\
(0.035)\end{array}$ & $\begin{array}{c}0.057 \\
(0.040)\end{array}$ & $\begin{array}{c}0.057 \\
(0.039)\end{array}$ & $\begin{array}{c}0.052 \\
(0.033)\end{array}$ & $\begin{array}{c}0.057 \\
(0.040)\end{array}$ & $\begin{array}{c}0.053 \\
(0.038)\end{array}$ \\
\hline $\begin{array}{l}\text { Uninsured Rate * Post * } \\
\text { Medicaid Expansion }\end{array}$ & -- & $\begin{array}{l}-0.004 \\
(0.018)\end{array}$ & $\begin{array}{c}0.003 \\
(0.043)\end{array}$ & $\begin{array}{c}0.003 \\
(0.043)\end{array}$ & $\begin{array}{l}-0.004 \\
(0.042)\end{array}$ & $\begin{array}{l}-0.004 \\
(0.042)\end{array}$ & $\begin{array}{l}-0.008 \\
(0.041)\end{array}$ \\
\hline \multicolumn{8}{|c|}{ Implied Effects of ACA at Mean Pre-Treatment Uninsured Rates } \\
\hline $\begin{array}{l}\text { ACA without Medicaid } \\
\text { Expansion }\end{array}$ & $\begin{array}{l}0.019 * * * \\
(0.002)\end{array}$ & $\begin{array}{c}0.011 \\
(0.006)\end{array}$ & $\begin{array}{c}0.012 \\
(0.007)\end{array}$ & $\begin{array}{c}0.012 \\
(0.008)\end{array}$ & $\begin{array}{c}0.011 \\
(0.008)\end{array}$ & $\begin{array}{c}0.012 \\
(0.008)\end{array}$ & $\begin{array}{c}0.011 \\
(0.008)\end{array}$ \\
\hline Medicaid Expansion & $\begin{array}{c}-0.010 * * * \\
(0.003)\end{array}$ & $\begin{array}{l}-0.001 \\
(0.007)\end{array}$ & $\begin{array}{c}0.001 \\
(0.009)\end{array}$ & $\begin{array}{c}0.001 \\
(0.009)\end{array}$ & $\begin{array}{l}-0.001 \\
(0.009)\end{array}$ & $\begin{array}{l}-0.001 \\
(0.009)\end{array}$ & $\begin{array}{c}-0.002 \\
(0.008)\end{array}$ \\
\hline $\begin{array}{l}\text { Full ACA (with } \\
\text { Medicaid Expansion) }\end{array}$ & $\begin{array}{l}0.009 * * * \\
(0.002)\end{array}$ & $\begin{array}{c}0.010 * * \\
(0.004)\end{array}$ & $\begin{array}{l}0.012 * * * \\
(0.004)\end{array}$ & $\begin{array}{c}0.012 * * * \\
(0.003)\end{array}$ & $\begin{array}{c}0.010 * * \\
(0.003)\end{array}$ & $\begin{array}{l}0.011 * * * \\
(0.003)\end{array}$ & $\begin{array}{c}0.009 * * \\
(0.003)\end{array}$ \\
\hline Area Fixed Effects & YES & YES & YES & YES & YES & YES & YES \\
\hline Time Fixed Effects & NO & YES & YES & YES & YES & YES & YES \\
\hline Demographic Controls & YES & YES & YES & YES & YES & YES & YES \\
\hline Family Controls & YES & NO & YES & NO & NO & YES & YES \\
\hline Economic Controls & YES & NO & NO & YES & NO & YES & YES \\
\hline Exchange Controls & YES & NO & NO & NO & YES & YES & YES \\
\hline
\end{tabular}


Appendix Table A3 (online publication only) - Additional Specifications for Any Private Insurance

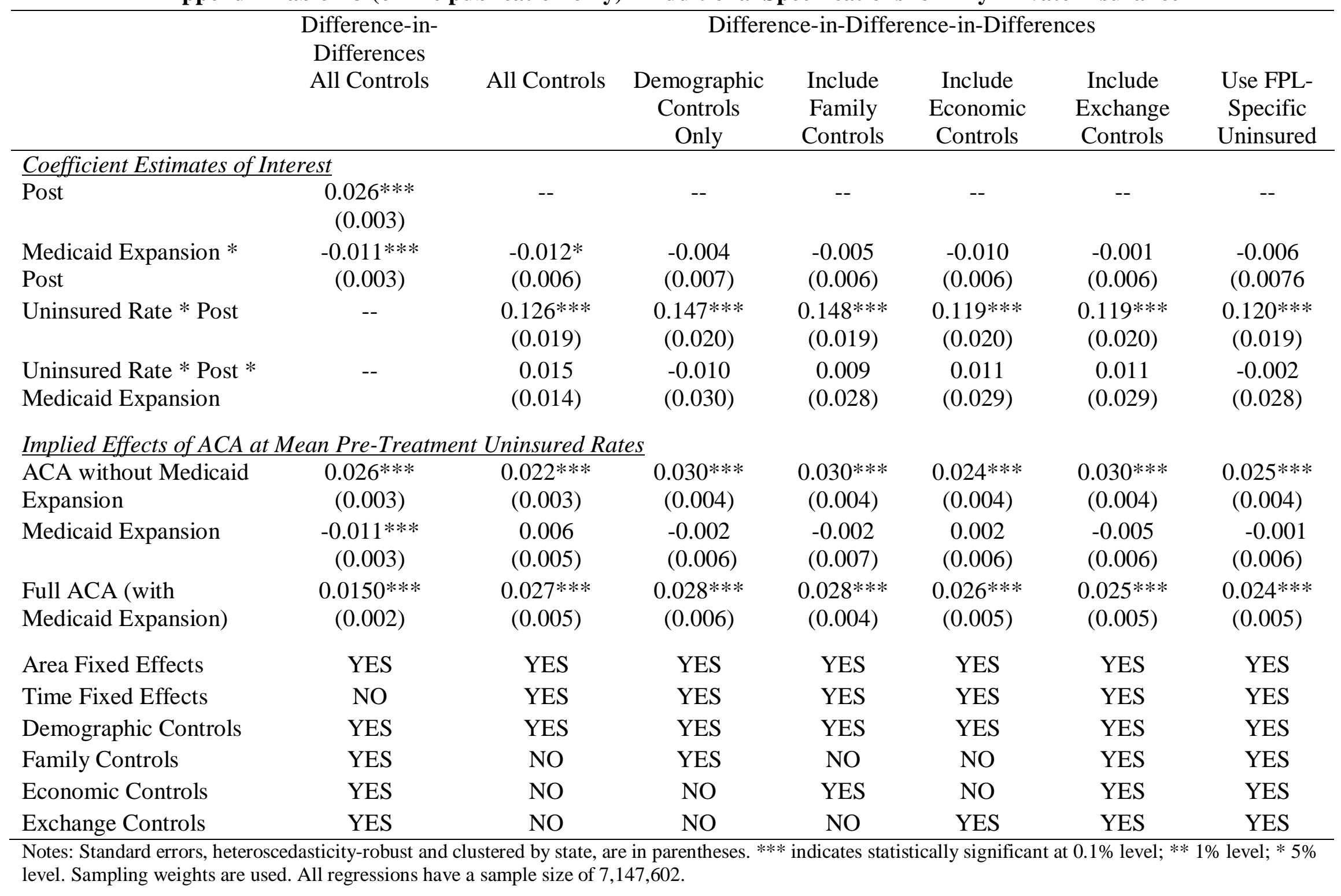


Appendix Table A4 (online publication only) - Additional Specifications for Medicaid

\begin{tabular}{|c|c|c|c|c|c|c|c|}
\hline & \multirow{2}{*}{$\begin{array}{l}\text { Difference-in- } \\
\text { Differences } \\
\text { All Controls }\end{array}$} & \multicolumn{6}{|c|}{ Difference-in-Difference-in-Differences } \\
\hline & & All Controls & $\begin{array}{c}\text { Demographic } \\
\text { Controls } \\
\text { Only }\end{array}$ & $\begin{array}{l}\text { Include } \\
\text { Family } \\
\text { Controls }\end{array}$ & $\begin{array}{l}\text { Include } \\
\text { Economic } \\
\text { Controls }\end{array}$ & $\begin{array}{l}\text { Include } \\
\text { Exchange } \\
\text { Controls }\end{array}$ & $\begin{array}{l}\text { Use FPL- } \\
\text { Specific } \\
\text { Uninsured }\end{array}$ \\
\hline \multicolumn{8}{|c|}{ Coefficient Estimates of Interest } \\
\hline Post & $\begin{array}{c}0.002 \\
(0.001)\end{array}$ & -- & -- & -- & -- & -- & -- \\
\hline Medicaid Expansion * & $0.030 * * *$ & 0.017 & -0.001 & 0.001 & 0.002 & -0.010 & -0.008 \\
\hline Post & $(0.004)$ & $(0.009)$ & $(0.008)$ & $(0.006)$ & $(0.006)$ & $(0.008)$ & $(0.008)$ \\
\hline Uninsured Rate * Post & -- & $\begin{array}{l}0.062^{*} \\
(0.028)\end{array}$ & $\begin{array}{l}0.017 \\
(0.020)\end{array}$ & $\begin{array}{c}0.017 \\
(0.020)\end{array}$ & $\begin{array}{l}0.0266 \\
(0.021)\end{array}$ & $\begin{array}{l}0.017 \\
(0.020)\end{array}$ & $\begin{array}{c}0.027 \\
(0.021)\end{array}$ \\
\hline $\begin{array}{l}\text { Uninsured Rate * Post * } \\
\text { Medicaid Expansion }\end{array}$ & -- & $\begin{array}{l}0.057 * \\
(0.028)\end{array}$ & $\begin{array}{l}0.155 * * * \\
(0.033)\end{array}$ & $\begin{array}{l}0.155^{* * * *} \\
(0.033)\end{array}$ & $\begin{array}{c}0.142 * * * \\
(0.034)\end{array}$ & $\begin{array}{c}0.168 * * * \\
(0.037)\end{array}$ & $\begin{array}{c}0.157 * * * \\
(0.038)\end{array}$ \\
\hline \multicolumn{8}{|c|}{ Implied Effects of ACA at Mean Pre-Treatment Uninsured Rates } \\
\hline $\begin{array}{l}\text { ACA without Medicaid } \\
\text { Expansion }\end{array}$ & $\begin{array}{c}0.002 \\
(0.001)\end{array}$ & $\begin{array}{l}0.011^{*} \\
(0.005)\end{array}$ & $\begin{array}{c}0.003 \\
(0.004)\end{array}$ & $\begin{array}{c}0.003 \\
(0.004)\end{array}$ & $\begin{array}{c}0.005 \\
(0.004)\end{array}$ & $\begin{array}{c}0.003 \\
(0.004)\end{array}$ & $\begin{array}{c}0.006 \\
(0.004)\end{array}$ \\
\hline Medicaid Expansion & $\begin{array}{c}0.030 * * * \\
(0.004)\end{array}$ & $\begin{array}{l}0.022 * \\
(0.009)\end{array}$ & $\begin{array}{c}0.032 * * * \\
(0.007)\end{array}$ & $\begin{array}{c}0.032 * * * \\
(0.007)\end{array}$ & $\begin{array}{c}0.029 * * * \\
(0.007)\end{array}$ & $\begin{array}{c}0.034 * * * \\
(0.008)\end{array}$ & $\begin{array}{c}0.032 * * * \\
(0.008)\end{array}$ \\
\hline $\begin{array}{l}\text { Full ACA (with } \\
\text { Medicaid Expansion) }\end{array}$ & $\begin{array}{l}0.022 * * * \\
(0.004)\end{array}$ & $\begin{array}{l}0.032 * * * \\
(0.008)\end{array}$ & $\begin{array}{l}0.035^{* * * *} \\
(0.006)\end{array}$ & $\begin{array}{c}0.035^{* * *} * \\
(0.005)\end{array}$ & $\begin{array}{c}0.034 * * * \\
(0.006)\end{array}$ & $\begin{array}{c}0.038 * * * \\
(0.006)\end{array}$ & $\begin{array}{c}0.038 * * * \\
(0.007)\end{array}$ \\
\hline Area Fixed Effects & YES & YES & YES & YES & YES & YES & YES \\
\hline Time Fixed Effects & $\mathrm{NO}$ & YES & YES & YES & YES & YES & YES \\
\hline Demographic Controls & YES & YES & YES & YES & YES & YES & YES \\
\hline Family Controls & YES & $\mathrm{NO}$ & YES & NO & $\mathrm{NO}$ & YES & YES \\
\hline Economic Controls & YES & NO & NO & YES & NO & YES & YES \\
\hline Exchange Controls & YES & NO & NO & NO & YES & YES & YES \\
\hline
\end{tabular}


Appendix Table A5 (online publication only) - Additional Specifications for Other Insurance

\begin{tabular}{|c|c|c|c|c|c|c|c|}
\hline & \multirow{2}{*}{$\begin{array}{l}\text { Difference-in- } \\
\text { Differences } \\
\text { All Controls }\end{array}$} & \multicolumn{6}{|c|}{ Difference-in-Difference-in-Differences } \\
\hline & & All Controls & $\begin{array}{c}\text { Demographic } \\
\text { Controls } \\
\text { Only }\end{array}$ & $\begin{array}{l}\text { Include } \\
\text { Family } \\
\text { Controls }\end{array}$ & $\begin{array}{l}\text { Include } \\
\text { Economic } \\
\text { Controls }\end{array}$ & $\begin{array}{l}\text { Include } \\
\text { Exchange } \\
\text { Controls }\end{array}$ & $\begin{array}{l}\text { Use FPL- } \\
\text { Specific } \\
\text { Uninsured }\end{array}$ \\
\hline \multicolumn{8}{|c|}{ Coefficient Estimates of Interest } \\
\hline Post & $\begin{array}{c}0.001 \\
(0.001)\end{array}$ & -- & -- & -- & -- & -- & -- \\
\hline $\begin{array}{l}\text { Medicaid Expansion * } \\
\text { Post }\end{array}$ & $\begin{array}{l}-0.001 \\
(0.001)\end{array}$ & $\begin{array}{c}0.002 \\
(0.002)\end{array}$ & $\begin{array}{l}-0.001 \\
(0.001)\end{array}$ & $\begin{array}{l}-0.001 \\
(0.001)\end{array}$ & $\begin{array}{l}-0.001 \\
(0.002)\end{array}$ & $\begin{array}{l}-0.001 \\
(0.002)\end{array}$ & $\begin{array}{l}-0.001 \\
(0.002)\end{array}$ \\
\hline Uninsured Rate * Post & -- & $\begin{array}{c}0.004 \\
(0.004)\end{array}$ & $\begin{array}{c}0.002 \\
(0.004)\end{array}$ & $\begin{array}{l}-0.002 \\
(0.004)\end{array}$ & $\begin{array}{l}-0.001 \\
(0.004)\end{array}$ & $\begin{array}{l}-0.002 \\
(0.004)\end{array}$ & $\begin{array}{l}-0.001 \\
(0.004)\end{array}$ \\
\hline $\begin{array}{l}\text { Uninsured Rate * Post * } \\
\text { Medicaid Expansion }\end{array}$ & -- & $\begin{array}{l}-0.004 \\
(0.004)\end{array}$ & $\begin{array}{c}0.001 \\
(0.006)\end{array}$ & $\begin{array}{c}0.006 \\
(0.006)\end{array}$ & $\begin{array}{c}0.005 \\
(0.006)\end{array}$ & $\begin{array}{c}0.004 \\
(0.006)\end{array}$ & $\begin{array}{l}-0.003 \\
(0.006)\end{array}$ \\
\hline \multicolumn{8}{|c|}{ Implied Effects of ACA at Mean Pre-Treatment Uninsured Rates } \\
\hline $\begin{array}{l}\text { ACA without Medicaid } \\
\text { Expansion }\end{array}$ & $\begin{array}{c}0.001 \\
(0.001)\end{array}$ & $\begin{array}{c}0.001 \\
(0.001)\end{array}$ & $\begin{array}{l}-0.001 \\
(0.001)\end{array}$ & $\begin{array}{l}-0.001 \\
(0.001)\end{array}$ & $\begin{array}{l}-0.001 \\
(0.001)\end{array}$ & $\begin{array}{l}-0.001 \\
(0.001)\end{array}$ & $\begin{array}{l}-0.001 \\
(0.001)\end{array}$ \\
\hline Medicaid Expansion & $\begin{array}{l}-0.000 \\
(0.001)\end{array}$ & $\begin{array}{l}-0.001 \\
(0.001)\end{array}$ & $\begin{array}{c}0.001 \\
(0.001)\end{array}$ & $\begin{array}{c}0.001 \\
(0.0021\end{array}$ & $\begin{array}{c}0.001 \\
(0.001)\end{array}$ & $\begin{array}{c}0.001 \\
(0.001)\end{array}$ & $\begin{array}{c}0.001 \\
(0.001)\end{array}$ \\
\hline $\begin{array}{l}\text { Full ACA (with } \\
\text { Medicaid Expansion) }\end{array}$ & $\begin{array}{c}0.001 \\
(0.001)\end{array}$ & $\begin{array}{l}-0.001 \\
(0.001)\end{array}$ & $\begin{array}{c}0.001 \\
(0.001)\end{array}$ & $\begin{array}{c}0.001 \\
(0.001)\end{array}$ & $\begin{array}{c}0.001 \\
(0.001)\end{array}$ & $\begin{array}{c}0.000 \\
(0.001)\end{array}$ & $\begin{array}{c}0.001 \\
(0.001)\end{array}$ \\
\hline Area Fixed Effects & YES & YES & YES & YES & YES & YES & YES \\
\hline Time Fixed Effects & NO & YES & YES & YES & YES & YES & YES \\
\hline Demographic Controls & YES & YES & YES & YES & YES & YES & YES \\
\hline Family Controls & YES & $\mathrm{NO}$ & YES & NO & $\mathrm{NO}$ & YES & YES \\
\hline Economic Controls & YES & NO & NO & YES & NO & YES & YES \\
\hline Exchange Controls & YES & NO & NO & NO & YES & YES & YES \\
\hline
\end{tabular}


Appendix Table A6 (online publication only) - Gender Subsamples

\begin{tabular}{|c|c|c|c|c|c|c|}
\hline & $\begin{array}{c}\text { Any } \\
\text { Insurance }\end{array}$ & $\begin{array}{c}\text { Any } \\
\text { Private }\end{array}$ & $\begin{array}{l}\text { Employer- } \\
\text { Provided }\end{array}$ & $\begin{array}{c}\text { Individ- } \\
\text { ually } \\
\text { Purchased }\end{array}$ & Medicaid & Other \\
\hline \multicolumn{7}{|c|}{ Women (Pre-Treatment Uninsured Rate $=0.185$ ) } \\
\hline $\begin{array}{l}\text { ACA w/o } \\
\text { Medicaid }\end{array}$ & $\begin{array}{c}0.028^{* * * *} \\
(0.006)\end{array}$ & $\begin{array}{c}0.020 * * * \\
(0.003)\end{array}$ & $\begin{array}{l}0.010^{*} \\
(0.004)\end{array}$ & $\begin{array}{c}0.008 \\
(0.006)\end{array}$ & $\begin{array}{c}0.006 \\
(0.005)\end{array}$ & $\begin{array}{c}0.001 \\
(0.001)\end{array}$ \\
\hline $\begin{array}{l}\text { Medicaid } \\
\text { Expansion }\end{array}$ & $\begin{array}{c}0.031 * * * \\
(0.007)\end{array}$ & $\begin{array}{c}0.001 \\
(0.006)\end{array}$ & $\begin{array}{c}0.003 \\
(0.006)\end{array}$ & $\begin{array}{l}-0.002 \\
(0.007)\end{array}$ & $\begin{array}{c}0.033 * * * \\
(0.009)\end{array}$ & $\begin{array}{c}0.001 \\
(0.001)\end{array}$ \\
\hline $\begin{array}{l}\text { Full ACA (w/ } \\
\text { Medicaid) }\end{array}$ & $\begin{array}{c}0.059 * * * \\
(0.005)\end{array}$ & $\begin{array}{c}0.022 * * * \\
(0.005)\end{array}$ & $\begin{array}{l}0.013 * * \\
(0.004)\end{array}$ & $\begin{array}{l}0.007 * \\
(0.003)\end{array}$ & $\begin{array}{c}0.040^{* * * *} \\
(0.007)\end{array}$ & $\begin{array}{c}0.001 \\
(0.001)\end{array}$ \\
\hline Sample Size & $3,700,757$ & $3,700,757$ & $3,700,757$ & $3,700,757$ & $3,700,757$ & $3,700,757$ \\
\hline \multicolumn{7}{|c|}{ Men $($ Pre-Treatment Uninsured Rate $=0.222)$} \\
\hline $\begin{array}{l}\text { ACA w/o } \\
\text { Medicaid }\end{array}$ & $\begin{array}{c}0.033 * * * \\
(0.005)\end{array}$ & $\begin{array}{c}0.030 * * * \\
(0.005)\end{array}$ & $\begin{array}{l}0.016^{* *} \\
(0.005)\end{array}$ & $\begin{array}{c}0.013 \\
(0.009)\end{array}$ & $\begin{array}{c}0.004 \\
(0.003)\end{array}$ & $\begin{array}{l}-0.001 \\
(0.001)\end{array}$ \\
\hline $\begin{array}{l}\text { Medicaid } \\
\text { Expansion }\end{array}$ & $\begin{array}{c}0.026 * * * \\
(0.007)\end{array}$ & $\begin{array}{l}-0.003 \\
(0.006)\end{array}$ & $\begin{array}{c}0.003 \\
(0.007)\end{array}$ & $\begin{array}{c}-0.002 \\
(0.010)\end{array}$ & $\begin{array}{c}0.029 * * * \\
(0.007)\end{array}$ & $\begin{array}{c}0.001 \\
(0.002)\end{array}$ \\
\hline $\begin{array}{l}\text { Full ACA (w/ } \\
\text { Medicaid) }\end{array}$ & $\begin{array}{c}0.059^{* * *} \\
(0.004)\end{array}$ & $\begin{array}{c}0.027 * * * \\
(0.005)\end{array}$ & $\begin{array}{c}0.019 * * * \\
(0.004)\end{array}$ & $\begin{array}{c}0.011^{* * *} \\
(0.003)\end{array}$ & $\begin{array}{c}0.034 * * * \\
(0.006)\end{array}$ & $\begin{array}{l}0.0003 \\
(0.002)\end{array}$ \\
\hline Sample Size & $3,446,845$ & $3,446,845$ & $3,446,845$ & $3,446,845$ & $3,446,845$ & $3,446,845$ \\
\hline
\end{tabular}

Notes: Standard errors, heteroscedasticity-robust and clustered by state, are in parentheses. *** indicates statistically significant at $0.1 \%$ level; ** $1 \%$ level; * 5\% level. Sampling weights are used. All regressions include state and time fixed effects, demographic and economic controls, and the interactions of the controls with post. 